\title{
Traceless Click-Assisted Native Chemical Ligation Enabled by Protecting Dibenzocyclooctyne from Acid- Mediated Rearrangement with Copper(I)
}

\author{
Patrick W. Erickson ${ }^{\ddagger \dagger}$, James M. Fulcher ${ }^{\ddagger \dagger \S}$, Michael S. Kay ${ }^{\dagger *}$ \\ tDepartment of Biochemistry, University of Utah School of Medicine, 15 North Medical \\ Drive East, Room 4100, Salt Lake City, Utah 84112-5650, United States
}

Keywords:

Chemical Protein Synthesis, CPS, Native Chemical Ligation, NCL, Click-Assisted NCL, CAN, Traceless Templated Peptide Ligation, Strain-Promoted Alkyne-Azide Cycloadditions, SPAAC, Copper-free Click Chemistry, DBCO, ADIBO, Tetrakis(acetonitrile)copper(I) Tetrafluoroborate, Helping Hand Lysine Linker, Ddap, Ribosome. 


\begin{abstract}
Chemoselective ligation reactions, such as native chemical ligation (NCL), enable the assembly of synthetic peptides into proteins. However, the scope of proteins accessible to total chemical synthesis is limited by ligation efficiency. Sterically hindered thioesters and poorly soluble peptides can undergo incomplete ligations, leading to challenging purifications with low yields. This work describes a new method, $\underline{\text { Click- }}$ Assisted Nㅡ (CAN), which overcomes these barriers. In CAN, peptides are modified with traceless "helping hand" lysine linkers that enable addition of dibenzocyclooctyne (DBCO) and azide handles for strain-promoted alkyne-azide cycloaddition (SPAAC) reactions. This cycloaddition templates the peptides to increase their effective concentration and greatly accelerate ligation kinetics. After ligation, mild hydroxylamine treatment tracelessly removes the linkers to afford the native ligated peptide. Although DBCO is incompatible with standard Fmoc solid-phase peptide synthesis (SPPS) due to an acid-mediated rearrangement that occurs during peptide cleavage, we demonstrate that copper(I) protects DBCO from this side reaction, enabling direct production of DBCO-containing synthetic peptides. Excitingly, low concentrations of triazole-linked model peptides reacted $\sim 1,200$-fold faster than predicted for non-templated control ligations, which also accumulated many side products due to the long reaction time. Using the E. coli ribosomal subunit L32 as a model protein, we further demonstrate that the SPAAC, ligation, desulfurization, and linker cleavage steps can be performed in a one-pot fashion. CAN will be useful for overcoming ligation challenges to expand the reach of chemical protein synthesis.
\end{abstract}




\section{INTRODUCTION}

The combination of solid-phase peptide synthesis (SPPS) ${ }^{1}$ with chemoselective ligation reactions enables the chemical synthesis of uniquely modified proteins. Of the chemoselective ligation strategies available, the Kent group's native chemical ligation (NCL) has proven to be highly robust and is widely used in the chemical synthesis of proteins. ${ }^{2-3}$ With $\mathrm{NCL}$, peptide segments bearing an $\mathrm{N}$-terminal Cys and C-terminal thioester can be chemoselectively ligated to generate synthetic proteins. NCL has been extended beyond Cys junctions via free-radical desulfurization, a robust technique that allows the more common Ala, as well as other amino acids amenable to thiol surrogates, to be used as ligation junctions..$^{4-5} \mathrm{NCL}$ has produced many useful synthetic proteins,${ }^{6-7}$ including targets for mirror-image drug discovery, ${ }^{8-12}$ functional native and mirror-image enzymes, ${ }^{13-18}$ mirror-image proteins for racemic crystallography, ${ }^{19-22}$ and proteins containing complex post-translational modifications. ${ }^{23-26}$

However, NCL has several challenges that limit its scope in chemical protein synthesis (CPS) ${ }^{7,27}$ First, NCL requires high peptide concentrations, typically $\geq 1 \mathrm{mM}$, at neutral $\mathrm{pH}$ for efficient ligation. Unfortunately, peptide segments are often too insoluble to reach these ideal concentrations, even in denaturing conditions. ${ }^{28}$ While many groups have developed strategies to increase peptide solubility, ${ }^{28-31}$ these do not overcome the inherent issue of requiring high concentrations. ${ }^{32}$ Additionally, the availability of suitable Cys or Ala ligation junctions is limited for many synthesis projects, forcing the selection of suboptimal segments for NCL. ${ }^{11,33}$ Although alternative thiolcontaining amino acids, such as penicillamine (thiol derivative of Val), can be used as junctions to increase access to alternative ligation strategies, these often suffer from 
slow ligation rates. ${ }^{34-36}$ In cases where limited suitable junctions exist, the use of sterically hindered thioesters may be required (e.g., Thr, lle, and Val). ${ }^{36-38}$ Even under ideal NCL conditions, sterically hindered thioesters suffer from long reaction times that often result in loss of peptide because of competing side reactions, creating complex HPLC purifications that further lower yields. The NCL rate is also dependent on the type of thioester used. ${ }^{39}$ Most commonly, 4-mercaptophenylacetic acid (MPAA) is used for NCL due to its favorable transthioesterification kinetics. ${ }^{40}$ However, MPAA has several disadvantages, including strong near-UV absorbance and potential co-elution with products in RP-HPLC. Several alternatives can be used in place of MPAA to avoid coelution with peptide, though at the cost of slower NCL kinetics. ${ }^{41-43}$

Templated ligation strategies can overcome these major barriers by increasing the proximity of the reactive partners, the C-terminal thioester and the $\mathrm{N}$-terminal thiol, thereby increasing their effective concentration (Scheme 1A). Templated ligations occur in an intramolecular fashion, converting reaction kinetics from $2^{\text {nd }}$ to $1^{\text {st }}$ order. An early example of such a proximity-driven reaction was demonstrated with Kemp's thiol capture. ${ }^{44-45}$ Effectively, templated ligations are macrocyclization reactions, a strategy commonly found in the synthesis of cyclic natural products and other compounds. ${ }^{46-49}$ Importantly, application of this strategy can improve the efficiency of slow thioesters and enable ligations at dramatically lower peptide concentrations, especially helpful for poorly soluble peptides.

Several templated ligation strategies have been developed, but specific caveats currently limit the utility of each strategy for CPS. Protein-templated ligations were the first demonstration of templated NCL, as peptides containing specific secondary 
structures can be brought into close proximity via their non-covalent interactions..$^{50-57}$ While protein-templated ligation works well in a variety of contexts (e.g., self-replicating peptides, conformationally assisted protein ligations, and labeling of cell membrane proteins), the method is infeasible for most CPS applications, as peptides do not usually self-associate, and denaturants are typically required for peptide solubilization. Nucleic acids and peptide nucleic acids (PNAs) have also been used for templated ligations, as peptides conjugated with DNA or PNA can be brought into proximity via specific basepairing interactions ${ }^{58-63}$ Nucleic acid-templated ligations complete quickly with only $\mathrm{nM}$ pM template, but DNA/PNA linkers cannot be removed from ligated product. In addition, this method has only been used in non-denaturing buffers, predominantly with short peptide sequences (<20 residues) that do not fully represent the diversity of amino acid functional groups. Recently, several traceless templated ligation strategies have been developed. One such method uses peptides functionalized with UV-cleavable linkers attached to either $\mathrm{PNA}^{64}$ or $\mathrm{DNA}{ }^{65}$ handles to enable templated ligation at low peptide concentrations. This method is not yet robust enough for routine CPS applications, as the linker syntheses are intricate, and the required UV irradiation and copper-catalyzed click steps may cause oxidative damage. ${ }^{66-68}$ The Bode group has also designed a traceless templated ligation using streptavidin-binding linkers, which cleave upon amide bond formation. ${ }^{69}$ Although this strategy is promising, complex linker synthesis is currently needed, and the methodology has not yet been demonstrated on peptides.

\section{A New Strategy for Traceless Templated Ligations}


We propose that the following fundamental elements are required for a traceless templated ligation strategy to be broadly applicable in CPS:

1) Simple and robust bioorthogonal linker synthesis

2) Bioorthogonal chemistry can be performed in typical peptide-solubilizing denaturants (e.g., $6 \mathrm{M}$ guanidine)

3) Bioorthogonal linkers are stable to commonly encountered CPS conditions (e.g., resin cleavage, ligation, and desulfurization)

4) Removal of bioorthogonal linkers is chemoselective, traceless, and efficient

5) Flexible positioning of bioorthogonal linkers within peptide sequences (e.g., placement not restricted to termini or infrequent amino acids)

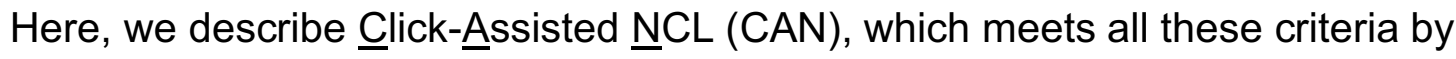
combining a traceless "helping hand" Lys linker (Ddap) ${ }^{70}$ with the bioorthogonal strained-click pair dibenzocyclooctyne (DBCO) and azide (Scheme 1B). In the CAN strategy, peptide segments are first coupled with a Ddap linker on a Lys sidechain onresin during SPPS before functionalization with either DBCO or azide. After resin cleavage and HPLC purification, the DBCO/azide-bearing peptides are combined for SPAAC. The resultant triazole linkage effectively templates the C-terminal thioester and $\mathrm{N}$-terminal thiol for ligation, increasing their effective concentration and allowing NCL to proceed with high efficiency. After ligation, mild hydroxylamine treatment chemoselectively removes the templating linkers, ${ }^{70}$ affording the native ligated peptide. Using model peptides, we show that the CAN strategy is compatible with all canonical 
amino acids (although Met is slightly more prone to oxidation). CAN also greatly accelerates ligation in the context of sterically hindered thioesters. Furthermore, these demonstrations use methyl thioglycolate (MTG) as a slower, relative to MPAA, but desulfurization-compatible thiol additive for NCL. ${ }^{71}$ Finally, we illustrate the utility of CAN for CPS by performing a strain-promoted click reaction, NCL, desulfurization, and linker cleavage to produce the $E$. coli $50 S$ ribosomal subunit L32 in one pot. 


\section{RESULTS AND DISCUSSION \\ Synthesis of DBCO Peptides via Fmoc-SPPS}

In order for CAN to be a robust CPS technique, peptides need to be templated together through a bioorthogonal reaction that will not cause unintended side reactions during conjugation. For this purpose, we chose to use strain-promoted alkyne-azide cycloaddition (SPAAC) $)^{72-73}$ over copper-catalyzed azide-alkyne cycloaddition (CuAAC) $)^{74-75}$ because SPAAC avoids potential copper-catalyzed oxidation during the click reaction. ${ }^{67-68}$ In addition, we wanted to perform one-pot templating and NCL and expected that the presence of copper within NCL conditions may cause side-product formation (e.g., during in situ thioester formation ${ }^{76}$ ).

The first obstacle to developing CAN was generating a robust, SPPS-compatible method for installing azide and DBCO cycloaddition partners. While azide-containing peptides can routinely be synthesized via SPPS, ${ }^{77} \mathrm{DBCO}$ peptides have only been synthesized using post-cleavage couplings, such as thiol-maleimide ${ }^{78-80}$ or amine-NHS ester. ${ }^{81}$ These post-cleavage workarounds are necessary because DBCO undergoes an inactivating rearrangement under the strongly acidic conditions, 95\% trifluoroacetic acid (TFA), used for peptide deprotection and cleavage from the resin. ${ }^{79-80,82-83}$ This rearrangement has been demonstrated in $\mathrm{DBCO}$ and related biarylazacyclooctynones and is thought to result from an acid-catalyzed 5-endo-dig cycloisomerization. ${ }^{83-84}$ Longer peptides are unlikely to have a single primary amine or thiol for post-cleavage couplings, so DBCO needs to be incorporated during Fmoc-SPPS. While DBCO can withstand lower TFA concentrations $(<30 \%),{ }^{82,85-86}$ most commonly used protecting groups and resins require higher TFA for efficient removal. We set out to investigate the 
stability of DBCO in standard TFA cleavage conditions using the model peptides $\mathrm{H}$ $\mathrm{C}(\mathrm{StBu}) \mathrm{GK}(\mathrm{DBCO}) \mathrm{ENTWY}-\mathrm{R}\left(\mathrm{R}=\mathrm{NH}_{2} \mathbf{1 a}, \mathrm{OH} \mathbf{1 b}\right.$, or $\mathrm{NHNH}_{2} \mathbf{1 c}$; see Table $\mathbf{S 1}$ for all peptide sequences) and Ac-RRRYSTEVEK(DBCO)NV-NHNH 2 2a (DBCO coupled to Lys side chains and Cys protected with StBu to prevent potential thiol-yne reactions). ${ }^{87}$ Our initial attempts to synthesize 1a via Fmoc-SPPS using a standard TFA peptide cleavage cocktail failed due to formation of an undetermined DBCO-related degradation product (Figure S1). 2a was found to have the correct molecular weight via LC/MS analysis (Figure S2). However, the DBCO moiety was unreactive when incubated with 6-azidohexanoic acid (Figure S3), suggesting it had undergone acid-catalyzed 5-endodig cycloisomerization. We did observe formation of the triazole through SPAAC before resin cleavage (Figure S4; see Table S2 for symbols used to denote common modifications such as triazole), indicating that DBCO degraded during cleavage and not during on-resin coupling.

The Hosoya group previously reported that a copper(I) salt, tetrakis(acetonitrile)copper(I) tetrafluoroborate or $(\mathrm{MeCN})_{4} \mathrm{CuBF}_{4}$, could reversibly protect cyclooctynes from reacting with azides. ${ }^{88-89}$ This strategy builds on the finding that various metals can form complexes with cycloalkyne rings, ${ }^{90}$ which led us to examine copper as an additive to prevent the acid-mediated 5-endo-dig cycloisomerization of DBCO. Guided by the methodology reported by the Hosoya group, initial attempts at protecting peptides $1 \mathbf{a}$ and $\mathbf{2} \mathbf{a}$ were performed by treating peptide resins with $\sim 3$ equiv. ( $M e C N$ ) ${ }_{4} \mathrm{CuBF}_{4}$ in dimethylformamide (DMF) for $1 \mathrm{~h}$. The resin was then washed with DMF and dichloromethane (DCM) before cleavage in the standard cocktail at $\mathrm{rt}$ for $3 \mathrm{~h}$. Standard ether precipitation and air drying produced the 
crude DBCO peptides. As envisioned, a transient DBCO-Cu complex was protected from acid-promoted ring rearrangement, and the resultant DBCO peptide product 1a was able to react with excess 6-azidohexanoic acid (Figure S5). However, we discovered that $(\mathrm{MeCN})_{4} \mathrm{CuBF}_{4}$ caused premature cleavage of peptides assembled on 2-chlorotrityl chloride resin. Additionally, the $\mathrm{Cu}(\mathrm{I})$ salt reacted with the $\mathrm{C}$-terminal hydrazide-containing peptide 2a to form undesired side products (Figure S6). Switching the solvents used to dissolve $(\mathrm{MeCN})_{4} \mathrm{CuBF}_{4}(\mathrm{DCM}, \mathrm{N}$-methylpyrrolidone, methanol, and $\mathrm{MeCN}$ ) did not overcome these side reactions (Figures S7-11).

To address this issue, we next tested the direct addition of $\sim 1.5$ equiv. $(\mathrm{MeCN})_{4} \mathrm{CuBF}_{4}$ to the peptide resin as a dry powder, immediately followed by addition of the TFA cleavage cocktail and incubation at rt for $3 \mathrm{~h}$ (Figure 1). Again, standard ether precipitation and air drying afforded the crude DBCO peptide 1a. Incubation of 1a with 6-azidohexanoic acid demonstrated a successful SPAAC (Figures 1 and S12). This simplified protection method was also successful in producing peptide $\mathbf{1 b}$ with reactive DBCO (Figure S13). However, while this method successfully generated hydrazide-containing $\mathbf{2 a}$ and $\mathbf{1 c}$, side reactions occurred when attempting to react crude 2a or 1c with 6-azidohexanoic acid (Figures S14-15). Copper test strips indicated that Cu was only partially removed during ether precipitation and was likely causing the undesired side reactions during SPAAC. Gratifyingly, HPLC purification appeared to remove the remaining $\mathrm{Cu}$, as pure $1 \mathrm{c}$ did not contain $\mathrm{Cu}$ (copper test strips), and the peptide successfully coupled with 6-azidohexanoic acid to afford the triazole with minimal side products (Figures S16-19). Inductively coupled plasma mass spectrometry (ICP-MS) confirmed removal of Cu, as several HPLC-purified DBCO 
peptides contained the same background Cu levels as peptides that were never exposed to the $\mathrm{Cu}(\mathrm{I})$ salt (Table S3).

\section{Robustness of the DBCO Protection Method}

Concerned with the potential of $\mathrm{Cu}(\mathrm{I})$ salts to oxidize certain amino acids, particularly Met and His, ${ }^{67}$ we examined the compatibility of the DBCO protection strategy using the more diverse model peptide $\mathrm{H}-\mathrm{C}(\mathrm{StBu}) \mathrm{DEAFGHIK}(\mathrm{DBCO}) \mathrm{LMNPQRSTVWYK}-\mathrm{NH}_{2} \mathbf{3 a}$ (and without DBCO, 3b), which contains every canonical amino acid. We found that thioanisole and 1,2ethanedithiol, two commonly used TFA cleavage scavengers that prevent Cys alkylation, diminished the protective properties of the $\mathrm{Cu}(\mathrm{I})$ additive with $3 \mathrm{a}$ (Figures

S20-25). Furthermore, we noted that ammonium iodide $\left(\mathrm{NH}_{4} \mathrm{l}\right)$, a cleavage additive used to reverse Met oxidation, ${ }^{91-92}$ was also capable of completely removing the StBuprotecting group on $\mathbf{3 a}$ and $\mathbf{3 b}$ (Figures $\mathbf{S 2 6 - 2 8}$ ). When $\mathbf{3 b}$ was cleaved in the presence or absence of $\sim 3$ equiv. $(\mathrm{MeCN})_{4} \mathrm{CuBF}_{4}$, the analytical HPLC and LC/MS chromatograms were similar (Figures 2A and S29-30). However, the presumed oxidation side-product $(+16 \mathrm{Da}$ ) increased from $6 \%$ to $12.5 \%$ in $\mathrm{Cu}(\mathrm{I})$-treated $\mathbf{3 b}$ (Figure 2A). Using trypsin digestion and high-resolution LC/MS/MS on $\mathbf{3 b} \pm \mathrm{Cu}(\mathrm{I})$ during cleavage, Met was identified as the oxidation-prone residue (Figure 2B). Furthermore, when the $\mathrm{Cu}(\mathrm{I})$ salt was used in the cleavage of model peptides $\mathrm{H}$ $\mathrm{C}(\mathrm{StBu})$ GKENTWYX-NH $\mathrm{H}_{2} \mathbf{4 a}(\mathrm{X}=\mathrm{H})$ and $\mathbf{4 b}(\mathrm{X}=\mathrm{M})$, oxidation was only observed in the Met-containing peptide $\mathbf{4 b}$ (Figures S31-32). While increased Met oxidation is a potential limitation of the DBCO protection method, all other canonical amino acids are 
fully compatible. In addition, Met is one of the least abundant amino acids and can typically be substituted with an isosteric norleucine (Nle) residue without affecting protein activity and folding. ${ }^{42,93-94}$

We next investigated the ideal concentration of the $(\mathrm{MeCN})_{4} \mathrm{CuBF}_{4}$ additive. Considering the objective of these experiments was to determine the amount of active DBCO following cleavage across a range of $(\mathrm{MeCN})_{4} \mathrm{CuBF}_{4}$ equivalents, the analysis was simplified by synthesizing 3a with a Met-to-Nle substitution to give oxidationresistant 3c (Figure 2C). 3c was incubated with the indicated amounts of $(\mathrm{MeCN})_{4} \mathrm{CuBF}_{4}$ in Figure $2 \mathrm{C}$ through standard cleavage conditions for $3 \mathrm{~h}$ before ether precipitation and air drying. Crude $3 c$ was then dissolved in HPLC buffer $(0.1 \%$ TFA, $18 \% \mathrm{MeCN}$ ) and coupled with excess 6 -azidohexanoic acid for $1 \mathrm{~h}$ at $37^{\circ} \mathrm{C}$ to determine the amount of reactive DBCO present (Figures $2 \mathrm{C}$ and $\mathbf{S 3 3 - 4 6 )}$. DBCO protection was observed to increase until 5 equiv. $(\mathrm{MeCN})_{4} \mathrm{CuBF}_{4}$. Surprisingly, 10 and 50 equiv. increased the amount of DBCO that failed to click with azide. This loss of reactivity may be attributed to excessive $\mathrm{Cu}(\mathrm{I})$ salts that are incompletely removed following ether precipitation, which could form a complex with the DBCO peptide, thus precluding efficient cycloaddition reactivity (Figures S39 and S46). Based on these optimizations, the use of 5 equiv. of $(\mathrm{MeCN})_{4} \mathrm{CuBF}_{4}$ was determined to be ideal for preventing the rearrangement of DBCO-containing peptides through standard cleavage conditions.

\section{Click-Assisted NCL with Model Peptides}

With a DBCO protection strategy in hand, we next investigated Click-Assisted NCL (CAN). We substituted the commonly used 4-mercaptophenylacetic acid (MPAA) 
thiol for methyl thioglycolate (MTG) during NCL, as MTG elutes in the void during RPHPLC, avoiding co-elution with peptide. Additionally, MTG is compatible with one-pot desulfurizations. ${ }^{71}$ Although MTG has slower ligation kinetics compared to MPAA,${ }^{71}$ we hypothesized that the effective concentration enhancement of the CAN strategy would render the choice of thiol additive less impactful. The non-templated control peptides STEVE (5a) and KENT (6a) were synthesized without SPAAC linkers to determine their in-solution NCL rate under representative conditions (Figure 3A). 5a was also designed with a C-terminal Val thioester, since they are known to be among the slowest in $\mathrm{NCL}$ due to steric hindrance. ${ }^{37-38}$ After $48 \mathrm{~h}$, the ligation reaction was incomplete and several side products had formed, with only $29 \%$ of the total HPLC peak area corresponding to ligated product 7 (Figures 3B and S47-52).

As a proof-of-concept for CAN, we then synthesized model peptides $\mathbf{5 b}$ and $\mathbf{6 b}$, each functionalized with the traceless Lys linker Ddap, ${ }^{70}$ a single Lys (to enhance solubility), and azide or DBCO as described in Scheme 1B. Equal amounts of purified $\mathbf{5 b}$ and $\mathbf{6 b}$ were dissolved together in $6 \mathrm{M} \mathrm{GnHCl}$ at $\mathrm{pH} 3$ to undergo SPAAC (Figures 4 and S53-58). Importantly, to the best of our knowledge, this is the first demonstration of SPAAC in denaturing conditions using guanidine. HPLC analysis revealed the presence of two triazole cycloadduct peptides (both referred to as 8). In this instance, the two distinguishable isobaric peaks are attributed to the two anticipated triazole regioisomers (Figures 4 and S57). Using comparable conditions to the non-templated reaction, the C-terminal hydrazide was converted to an MTG thioester in situ prior to performing CAN (0.5 mM 8, Figure 4). Excitingly, the ligation to form 9 was complete at $4 \mathrm{~h}$ (Figures 4 and S59-60), and the relative peak area of 9 from this CAN reaction was much higher 
(85\%) compared to the non-templated control NCL (29\%), attributable in part to significantly diminished side products (Figure 4). We then cleaved the Ddap linkers of 9 in one pot via the addition of hydroxylamine to $\sim 1 \mathrm{M}$ at pH 6.75 for $2 \mathrm{~h}$ (Figures 4 and S61). The native, ligated product without Ddap linkers was easily purified by HPLC to afford 7 (Figures 4 and S62). CAN with 8 was then repeated for a more precise kinetic analysis (Figures 5 and S63-65).

To investigate the impact of linker length on the CAN reaction rate, peptides $5 \mathrm{c}$ and 6c were each functionalized with Ddap, a single Lys, and a $\mathrm{PEG}_{8}$ linker before addition of their respective SPAAC partners. The $\mathrm{PEG}_{8}$ spacers double the total extended distance between the triazole-linked peptides. Using the same conditions as with $\mathbf{5 b}$ and $\mathbf{6 b}$, the $\mathrm{PEG}_{8}$ peptides first underwent SPAAC to give triazole-linked 10 (2.5 $\mathrm{mM}$ both peptides at $37^{\circ} \mathrm{C}$ for $2 \mathrm{~h}$, Figures S66-71) before performing CAN at $0.5 \mathrm{mM}$ to give ligated product 11 (Figures S72-73). This CAN with $\mathrm{PEG}_{8}$ spacers was $\sim 3$-fold slower than the non-PEGylated CAN (Figure 5).

One of the more attractive uses of CAN, and templated ligations in general, is the ability to perform ligations at lower peptide concentrations (i.e., the triazole-linkage renders the NCL an intramolecular reaction). To validate this property, we repeated CAN with 8 and $10\left( \pm P E G_{8}\right)$ at a 10 -fold lower concentration $(0.05 \mathrm{mM})$. We observed that a significant amount of the $\mathrm{N}$-terminal Cys peptide was being capped (initially +74 Da, Figures S74-77). The mass of this side product suggested that modification was the result of acylation from an MTG acyl donor. This acylation occurs negligibly in the $0.5 \mathrm{mM}$ CAN reactions, indicating that acylation occurs on a small amount of peptide that only becomes problematic at lower peptide concentrations. Therefore, we surmised 
that reducing the MTG concentration would reduce this side reaction. A ten-fold reduction in MTG concentration without proportional reduction of TCEP concentration, however, led to significant Cys desulfurization (Figures S78-80). Fortunately, a proportionate reduction of TCEP concentration eliminated this desulfurization. Using these conditions, CAN kinetics were similar for both the 0.05 and $0.5 \mathrm{mM}$ reactions (Figures 5 and S81-84). Compared to the non-templated NCL (0.4 mM 5a and $0.5 \mathrm{mM}$ 6a), the $0.05 \mathrm{mM} 8 \mathrm{CAN}$ reached completion $\sim 12 \mathrm{x}$ faster ( $4 \mathrm{~h}$ for CAN vs. $48 \mathrm{~h}$ for nontemplated $\mathrm{NCL}$ ). Based on the $2^{\text {nd }}$-order rate law, a 10-fold reduction in concentration of both peptides in the non-templated NCL would slow the reaction 100 -fold, which is too slow to measure and would likely be dominated by side reactions. Therefore, the 0.05 mM 8 CAN reached completion $\sim 1,200$-fold faster than expected for the non-templated $\mathrm{NCL}$ at the same concentration.

\section{Click-Assisted NCL of the E. coli 50 S ribosomal subunit L32}

To demonstrate the general utility of CAN in CPS, we pursued a representative protein target - the E. coli 50S ribosomal subunit L32 (Figure 6A). L32 is an ideal CAN choice for several reasons. First, the 56-residue L32 contains a reasonably placed ThrAla ligation junction (Figure 6A). Similar to the Val thioesters used above, Thr thioesters are sterically hindered and exhibit slow NCL kinetics. ${ }^{37-38}$ Furthermore, L32 lacks any native Cys residues, so desulfurization must be performed after NCL to produce native L32. This protein allows us to test four reactions (SPAAC, CAN, desulfurization, and Ddap linker cleavage) in a one-pot fashion (Scheme 2). Finally, L32-C (45-57) conveniently bears a Lys residue near its $\mathrm{N}$-terminus, and L32-N (2-44, 
removed initiator Met) contains Lys residues both proximal and distal to the C-terminal thioester, allowing us to investigate the impact of Ddap linker placement on CAN reaction rate (Scheme 2). Following the same procedure for the model peptide control reactions, we first performed a representative control NCL between peptide 12a (L32-N 2-44) and 13a (L32-C 45-57) that was nearly complete after $48 \mathrm{~h}$ (Figures 6B, 6C , and S85-90), with $70 \%$ of the peak area corresponding to ligated 14 a (Figure $6 \mathrm{C}$ ). Notably, a significant amount of $12 \mathrm{a}$ was lost due to thioester hydrolysis.

To investigate CAN for L32, L32-N (2-44) was functionalized with Ddap followed by a single Lys and 6-azidohexanoic acid at Lys ${ }^{37}$ (closer distance, 12b, L32-close) or Lys $^{12}$ (farther distance, 12c, L32-far) (Scheme 2). Nle was substituted for the sole Met ${ }^{15}$, as cleavage cocktails containing $\mathrm{NH}_{4}$ l additive were found to cause azide degradation (Figure S91), and we desired to avoid Met oxidation during peptide cleavage. L32-C (45-57) was functionalized at Lys ${ }^{53}$ with Ddap followed by a single Lys and DBCO-C6 to give 13b. We first investigated CAN of L32-close by clicking $12 \mathbf{b}$ with 13b in $6 \mathrm{M} \mathrm{GnHCl}$ at $\mathrm{pH} 3$ to give 15 (Figures 7 and S92-97), which has a distance of 15 AA between Lys Ddap linkers. CAN was then performed using the same ligation conditions as the non-templated L32 ligation ( $0.3 \mathrm{mM}$ of triazole-linked 15, Figure 7). 15 ligated to completion within $2 \mathrm{~h}$, much faster than the $48 \mathrm{~h}$ needed for the non-templated ligation. Furthermore, $88 \%$ of the peak area corresponded to ligated product 16 (Figures 7 and S98-99). Finally, we performed desulfurization to give 17 and Ddap linker cleavage to produce full-length L32 14b in a one-pot synthesis (Figures 7 and S100-102). 
To determine how placing Ddap linkers further from ligation junctions affects CAN rate, we investigated CAN of L32-far by performing SPAAC with $12 c$ and $13 b$ in 6 $\mathrm{M} \mathrm{GnHCl}$ at $\mathrm{pH} 3\left(1.7 \mathrm{mM}\right.$ both peptides at $37^{\circ} \mathrm{C}$ for $4 \mathrm{~h}$, Figures S103-106). L32-far CAN was then tested with $0.3 \mathrm{mM}$ of the triazole-linked 18 (distance of $40 \mathrm{AA}$ between Ddap linkers) under the same ligation conditions as L32-close. The L32-far CAN was complete after $6 \mathrm{~h}$ to give peptide 19 , compared to the $48 \mathrm{~h}$ non-templated ligation (Figures 8 and $\mathbf{S 1 0 7 - 1 0 8 ) . ~ T h e ~} 1^{\text {st }}$ order rate constant for L32-close (98-membered macrocycle) was 4.5-fold faster than for L32-far (173-membered macrocycle) (Figure 8).

The synthesis of L32 using CAN highlights some of the key features of this technique. First, implementing CAN into a synthesis project does not add extra intermediate HPLC purifications. Second, the distance between linker sites on the two peptides is quite flexible - the L32 ligation was separated by 40 AA yet still achieved a significant improvement in ligation rate relative to the non-templated NCL. Finally, CAN dramatically increases the throughput of CPS, as CAN enabled full-length, L32 to be easily HPLC purified in $\sim 25 \mathrm{~h}$ (including SPAAC, ligation, desulfurization, and linker removal), whereas the non-templated $\mathrm{L} 32 \mathrm{NCL}$ requires $48 \mathrm{~h}$ to reach completion and a subsequent desulfurization step. 


\section{CONCLUSIONS}

For the first time, DBCO peptides were directly synthesized via Fmoc-SPPS by using $(\mathrm{MeCN})_{4} \mathrm{CuBF}_{4}$ to protect $\mathrm{DBCO}$ from acid-mediated rearrangement during standard acid cleavage. This DBCO protection strategy was shown to be robust, as DBCO peptides with various C-terminal functional groups were successfully prepared on different resins. Furthermore, all canonical amino acids were compatible, although Met is slightly oxidation-prone. This DBCO protection method enabled development of Click-Assisted NCL (CAN), which is a traceless templated ligation strategy that can be used to dramatically increase NCL efficiency. Using the STEVE and KENT model peptides, CAN was estimated to be approximately 1,200 -fold faster than a nontemplated NCL at $0.05 \mathrm{mM}$. CAN also improved yield and reduced side products compared to non-templated NCL. The utility of CAN in CPS was also demonstrated through the preparation of the E. coli 50 S ribosomal subunit L32. Compared to nontemplated NCL, CAN enabled a faster ligation with one-pot SPAAC, ligation, desulfurization, and linker removal. Finally, the CAN rate was shown to modestly drop with template distance (i.e., increased macrocycle size), maintaining significant NCL rate enhancements even with distant attachment points - up to 40 AA separation demonstrated.

This new method to directly synthesize DBCO peptides via Fmoc-SPPS will be a useful tool for many peptide chemists. For example, peptide and protein nanoparticle conjugates have exciting biomedical applications (e.g., drug delivery and in vivo imaging), but there is a need to develop additional methods enabling site-specific incorporation of peptides onto nanoparticles. ${ }^{95} \mathrm{DBCO}$ peptides can be easily conjugated 
to azide-functionalized nanoparticles, ${ }^{82}$ and this method will enable larger and more sequence-diverse DBCO peptides to be incorporated. Additionally, several methods exist to incorporate azides into proteins via engineered tRNA synthetases or Met replacement with azide-containing analogs, ${ }^{96-100}$ enabling DBCO peptides to tag recombinant azido-proteins for various applications (e.g., proteome labeling and imaging). Although cyclooctynes can be genetically encoded into proteins, ${ }^{98,100-104}$ these methods are more challenging to implement compared to azide ${ }^{98}$ The finding that $(\mathrm{MeCN})_{4} \mathrm{CuBF}_{4}$ prevents acid-catalyzed 5-endo-dig cycloisomerization in DBCO, and perhaps other alkyne-derived isomerization reactions, ${ }^{105}$ is an important observation. For example, several groups have reported synthetic limitations when working with various strained alkynes due to the 5-endo-dig cycloisomerization, ${ }^{82-86}$ and protecting these strained alkynes with $(\mathrm{MeCN})_{4} \mathrm{CuBF}_{4}$ should increase the number of synthetic strategies available. This $(\mathrm{MeCN})_{4} \mathrm{CuBF}_{4}$ protection may also be effective in protecting DBCO peptides after resin cleavage and ether precipitation, as suggested by the 10 and 50 equiv. $(\mathrm{MeCN})_{4} \mathrm{CuBF}_{4}$ data shown in Figure $2 \mathrm{C}$. The larger quantities of $(\mathrm{MeCN})_{4} \mathrm{CuBF}_{4}$ in the cleavage solution appear to allow DBCO to remain protected after resin cleavage, as 6-azidohexanoic acid did not efficiently react with $\mathrm{DBCO}$ in aqueous conditions. Liberation of copper from the DBCO peptides could be accomplished with aqueous ammonia, EDTA, or metal scavengers, as reported by the Hosoya group. ${ }^{88-89}$ As other metal salts have been demonstrated to complex with cycloalkyne rings, ${ }^{90,} 106$ these may also be able to protect against acid-mediated degradation.

We expect CAN to find use as a tool in CPS for efficiently ligating peptides suffering from sluggish thioesters and/or poor solubility. Interestingly, since lower- 
concentration CAN is expected to maintain its ligation rate, the relative benefit of CAN over solution NCL will increase at further reduced peptide concentrations (e.g., compared to NCL at $500 \mathrm{nM}$, STEVE/KENT CAN is predicted to be $\sim 12,000,000$-fold faster). The current CAN methodology is expected to be applicable to many CPS strategies, especially since the reaction rate enhancement is relatively insensitive to linker attachment points. For example, $64 \%$ of all possible Cys and Ala ligation junctions in the E. coli 50S and 30 S ribosomal proteins are CAN-compatible (Lys within 20 AA's of the junction on both the $\mathrm{N}$ - and $\mathrm{C}$-terminal peptides). CAN will also be particularly useful for sluggish ligations using unnaturally thiolated amino acids that enable NCL outside of Cys, such as thiolated valine. ${ }^{34-35}$ Furthermore, CAN should be compatible with other peptide linker strategies, ${ }^{30-31}$ due to the simplicity of preparing both azide and DBCO peptides.

Future improvements to the CAN methodology have the potential to dramatically streamline CPS projects. For example, CAN currently requires relatively high peptide concentrations to efficiently perform SPAAC (typically $>50 \mu \mathrm{M}$ ) ${ }^{32}$ before NCL. Although we limited our demonstration to aqueous conditions with denaturant, it is worth noting that SPAAC is much more versatile than NCL since SPAAC can be performed in solvent mixtures more conducive for solubilizing peptides, such as $\mathrm{MeCN} / \mathrm{H}_{2} \mathrm{O}$ that is compatible with being directly lyophilized. ${ }^{107-108}$ Furthermore, unlike NCL, SPAAC does not suffer from competition with thioester hydrolysis. Future iterations of CAN may employ faster bioorthogonal chemistries for linking the peptides, as long as the chemistries are SPPS compatible. In fact, such bioorthogonal reactions that are also mutually orthogonal to DBCO and azide SPAAC would potentially enable multiple 
ligations to be performed in one pot via a CAN strategy. Such a combination would greatly increase yields in CPS by eliminating the need for intermediate HPLC purifications after each ligation. Finally, CAN parameters can be incorporated into an improved version of our "Automated Ligator" (Aligator) program, ${ }^{109}$ to predict segments that will benefit most from CAN. 


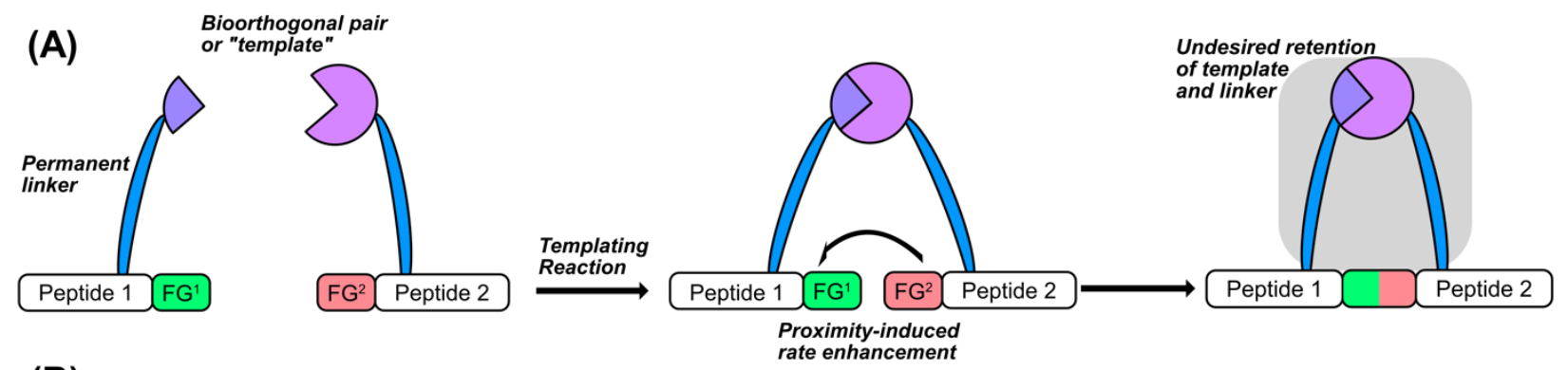

(B)

SPAAC Bioorthogonal pair
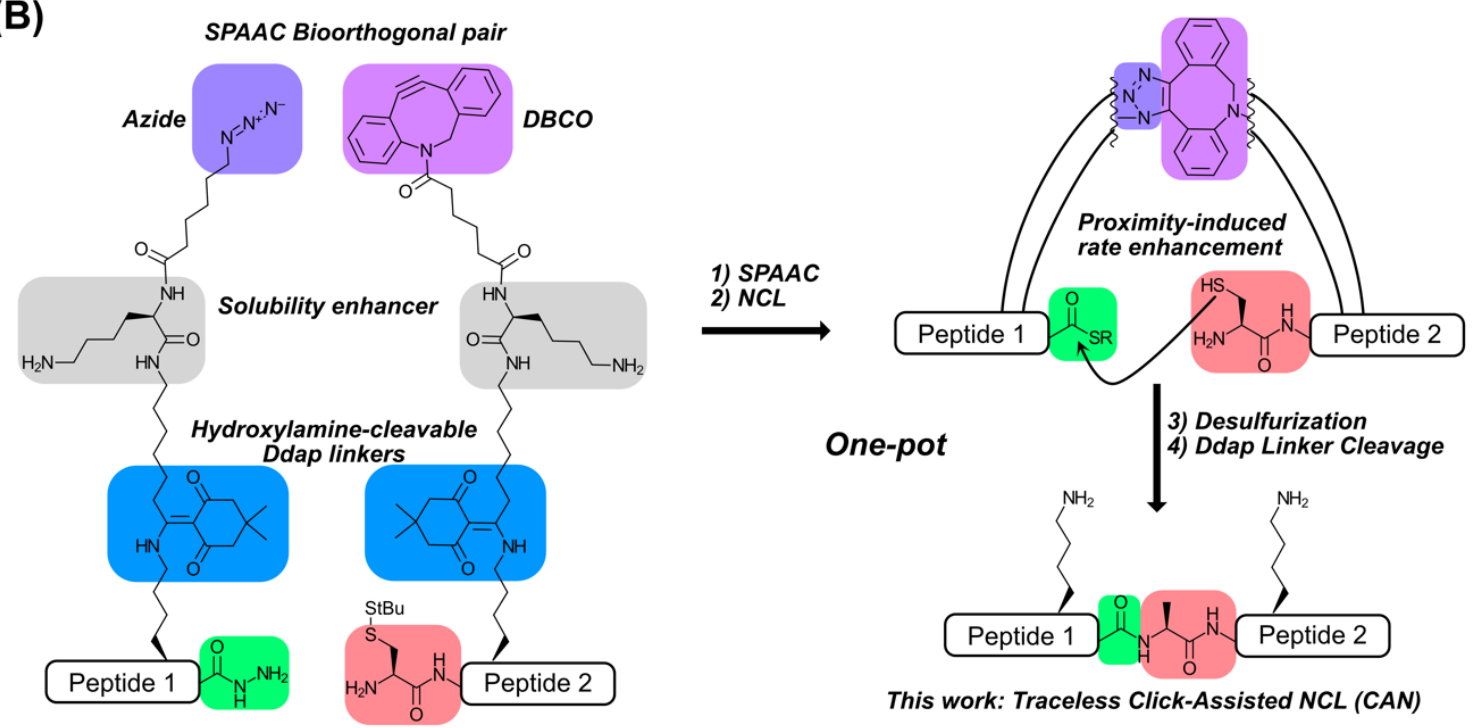

This work: Traceless Click-Assisted NCL (CAN)

Scheme 1: Overview of templated peptide ligation strategies. (A) Peptides functionalized with bioorthogonal groups are templated together, increasing the effective concentration of two functional groups (FG ${ }^{1}$ and $\mathrm{FG}^{2}$ ). While this strategy increases reaction efficiency, the bioorthogonal groups remain bound to the ligated peptide, leaving "scars" that are unacceptable for most CPS applications. (B) With Click-Assisted NCL (CAN), peptides functionalized with traceless Lys linkers (Ddap) and either DBCO or azide are first templated together via SPAAC. These templated peptides then undergo a proximity-enhanced NCL, desulfurization (if desired), and gentle hydroxylamine treatment to cleave the Ddap linker and tracelessly afford the native peptide. Importantly, all steps can be performed in one pot. 

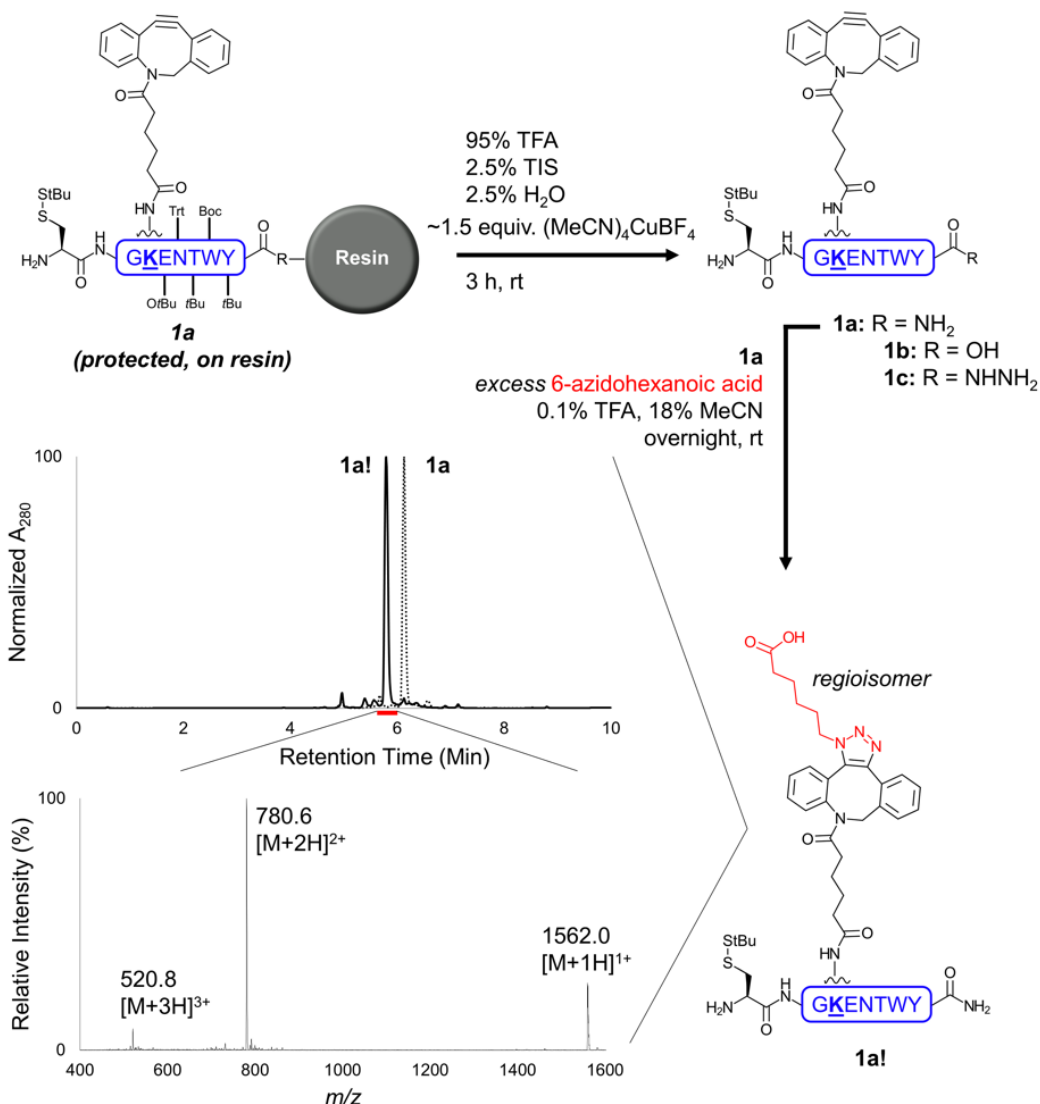

Figure 1: Protection of DBCO peptide 1a from acid-mediated degradation using $(\mathrm{MeCN})_{4} \mathrm{CuBF}_{4}$ in standard peptide cleavage conditions. This protection strategy generated a relatively clean crude peptide (dashed line in the LC/MS chromatogram) corresponding to the expected mass of 1a (observed mass: 1,401.9 Da, calculated average mass: 1,402.6 Da, Figure S12). This crude peptide successfully underwent SPAAC when incubated with excess 6-azidohexanoic acid, as the expected triazole formed (solid line in the LC/MS chromatogram, 1a!; observed mass: 1,559.9 Da, calculated average mass: 1,559.8 Da). LC/MS Method $\mathrm{C}$ was used. 
(A)

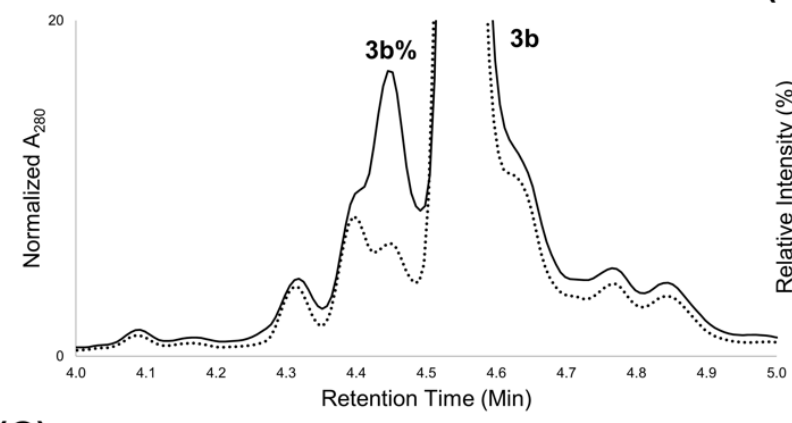

(C)
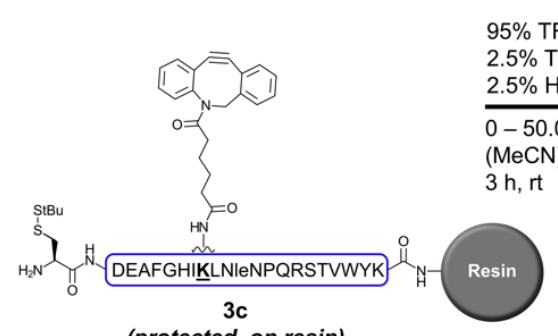

95\% TFA
$2.5 \%$ TIS

$2.5 \% \mathrm{H}_{2} \mathrm{O}$

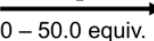
$(\mathrm{MeCN})_{4} \mathrm{CuBF}_{4}$

$\mathrm{h}, \mathrm{rt}$

(protected, on resin)
(B)

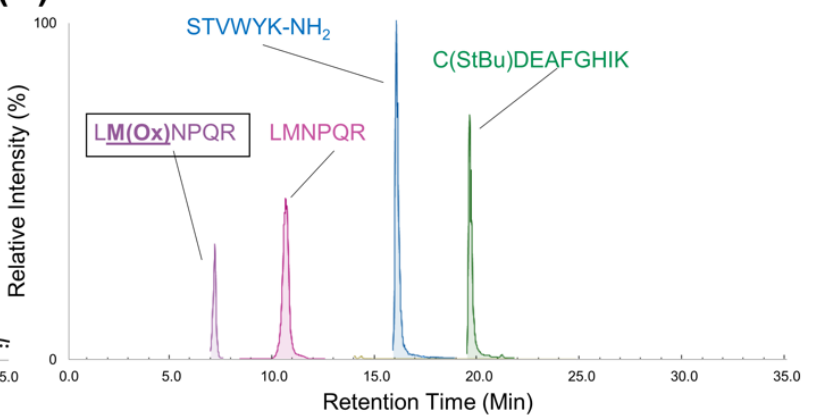

Figure 2: Assessment of the $(\mathrm{MeCN})_{4} \mathrm{CuBF}_{4} \mathrm{DBCO}$ protection strategy's robustness. Peptide $\mathbf{3 b}$ (all canonical residues represented) was used to determine the strategy's oxidation potential, and peptide 3c (Met-to-Nle variant of 3b) was used to establish effective amounts of $\mathrm{Cu}(\mathrm{I})$ salt to use for DBCO protection. (A) Overlaid LC/MS chromatogram showing $\mathbf{3 b}$ cleaved with (solid line) or without (dashed line) $\sim 3$ equiv. $\left(\mathrm{MeCN}_{4} \mathrm{CuBF}_{4}\right.$. Integration of the peak areas suggested oxidation $(\mathbf{3 b} \%)$ increased from $6 \%$ to $12.5 \%$ with $\mathrm{Cu}(\mathrm{I})$ salt addition to the standard cleavage cocktail. LC/MS Method C was used, and the individual chromatograms are shown in Figure S29. (B) Trypsin digestion and LC/MS/MS analysis of $\mathbf{3 b}$ revealed Met as the oxidation-susceptible residue. The $\mathbf{3 b}$ sequence is color-coded by trypsin-digested fragments and matches the appropriate ion signal identified through MS/MS analysis. LM(Ox)NPQR (far left peak, purple) indicates peptide containing oxidized Met. (C) Cleavage of $3 c$ with different equiv. of $(\mathrm{MeCN})_{4} \mathrm{CuBF}_{4}$ indicated that 5.0 equiv. provides the most effective DBCO protection. After performing SPAAC on crude $3 \mathbf{c}, \mathrm{A}_{280}$ peak areas of reacted (3c!) and unreacted peptide were integrated to calculate \% reactive DBCO. ${ }^{* * *}$ Indicates higher equiv. of $(\mathrm{MeCN})_{4} \mathrm{CuBF}_{4}$ that were found to complex with the DBCO peptide, preventing reaction with azide after cleavage. Although the \% reactive DBCO is lower, this decrease is not due to 5-endo-dig-cycloisomerization. LC/MS chromatograms of crude 3c (before and after SPAAC) are shown in Figures S33-46. 
(A)

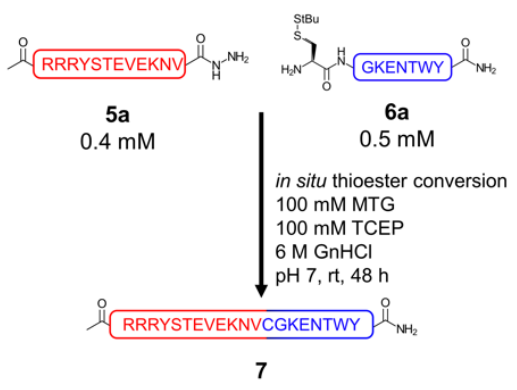

(B)

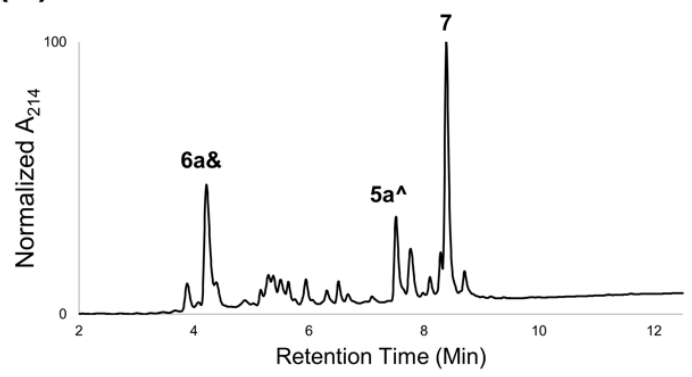

Figure 3: Non-templated native chemical ligation between purified $\mathbf{5 a}$ and $\mathbf{6 a}$. (A) Simplified schematic of the ligation. Note that MTG was allowed to form the thioester for $10 \mathrm{~min}$ prior to TCEP addition, as shown in the more detailed scheme (Scheme S1). (B) HPLC chromatogram of the ligation endpoint $(48 \mathrm{~h})$. $\mathbf{6} \mathbf{a} \boldsymbol{\&}$ refers to StBu-deprotected $\mathbf{6} \mathbf{a}$, and $\mathbf{5} \mathbf{a}^{\wedge}$ refers to $\mathbf{5 a}$ containing a C-terminal MTG thioester. After $48 \mathrm{~h}$ (from MTG addition), the reaction was incomplete, and numerous side products were observed. Analytical Method B was used. HPLC and LC/MS chromatograms of additional time points for this ligation are shown in Figures S5152. 


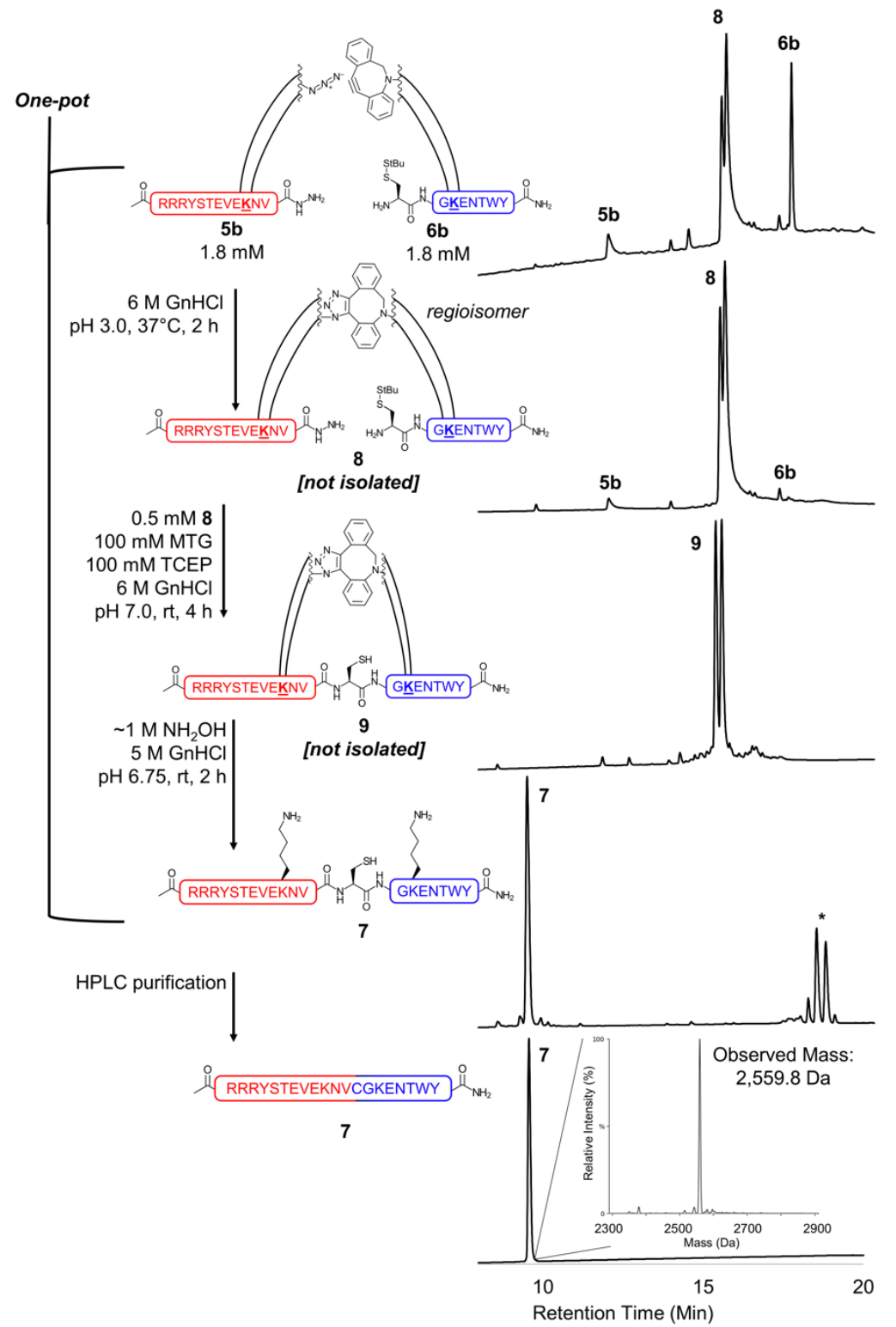

Figure 4: One-pot SPAAC, CAN, and linker cleavage. $5 \mathrm{~b}$ and $6 \mathrm{~b}$ were first templated together via $2 \mathrm{~h}$ SPAAC to produce triazole-linked 8 . CAN was then performed on 8 to efficiently generate 9 after only $4 \mathrm{~h}$. A $2 \mathrm{~h}$ linker cleavage of 9 resulted in native 7, which was easily HPLC purified. The HPLC chromatograms show, in descending order, 0 and $2 \mathrm{~h}$ SPAAC, $4 \mathrm{~h}$ CAN (after MTG addition), $2 \mathrm{~h}$ linker cleavage, and purified 7 . The double peaks observed after SPAAC and CAN are expected, as the triazole forms two regioisomers. * indicates cleaved Ddap linker peaks. There are four Ddap linker peaks due to the triazole regioisomer and a second nucleophilic addition via hydroxylamine on the Ddap dimedone ring. Note that unreacted STEVE and KENT peptides observed after linker cleavage do not stick to the column with the HPLC gradient used here (Figure S61 shows these unreacted peptides). The mass spectrum of purified 7 shows the correct full-length STEVEKENT peptide was generated (observed mass: 2,559.8 Da, calculated average mass: 2,559.9 Da). A more detailed one-pot reaction schematic is shown in Scheme S2. Analytical Method C and LC/MS Method C were used. HPLC and LC/MS chromatograms of additional time points are shown in Figures S57-62. 


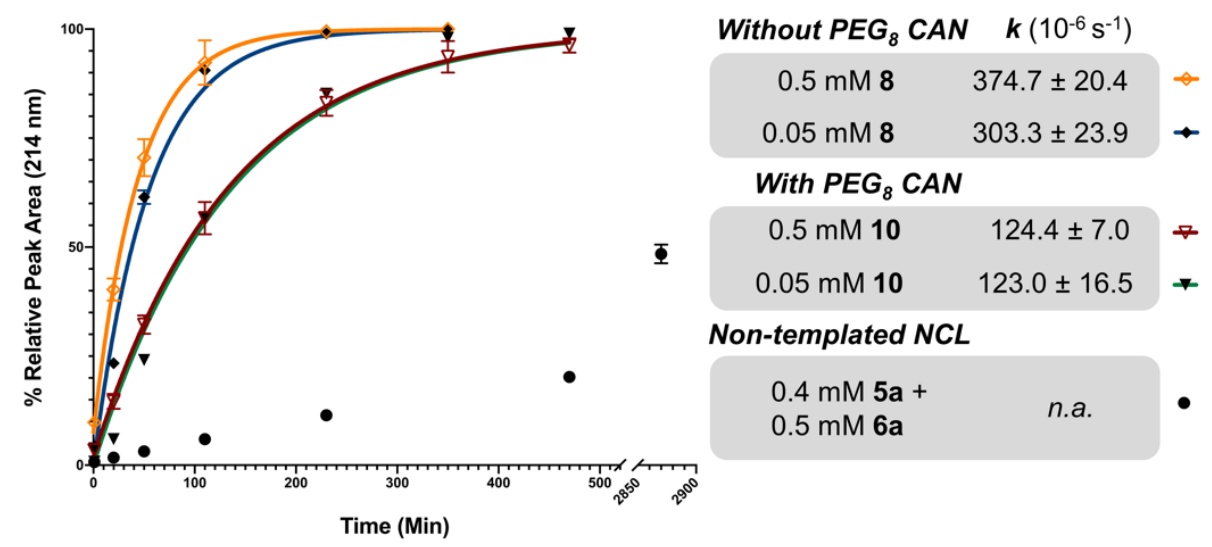

Figure 5: Comparison of non-templated NCL and CAN reaction rates. NCL or CAN was performed using the STEVE and KENT model peptides (5a, 6a, 8, and 10). The relative integrated peak area of ligated products are shown at various time points relative to TCEP addition (1, 20, 50, 110, 230, 350, 470, 1430, and $2870 \mathrm{~min})$. CAN ligations were fit to first-order rate constants. Note that the calculated rate constant for the $0.05 \mathrm{mM} 8 \mathrm{CAN}$ is slightly lower than expected due to the StBu protecting group being removed more slowly at the 10-fold lower TCEP concentration used. Importantly, the $8 \mathrm{CAN}$ is complete after $4 \mathrm{~h}$ at both peptide concentrations. For the non-templated NCL, peak areas of both product (7) and STEVE reactant $\left(5 \mathbf{a}^{\wedge}\right)$ were calculated using estimated extinction coefficients, as described in the supplemental methods. Each data point represents the average of two independent experiments, with the error bars corresponding to standard deviation. 
(A)

10

20

30

40

AVQQNKPTR SKRGMRRSHD ALTAVTSLSV DKTSGEKHLR

50

HHITADGYYR GRKVIAK

(B)
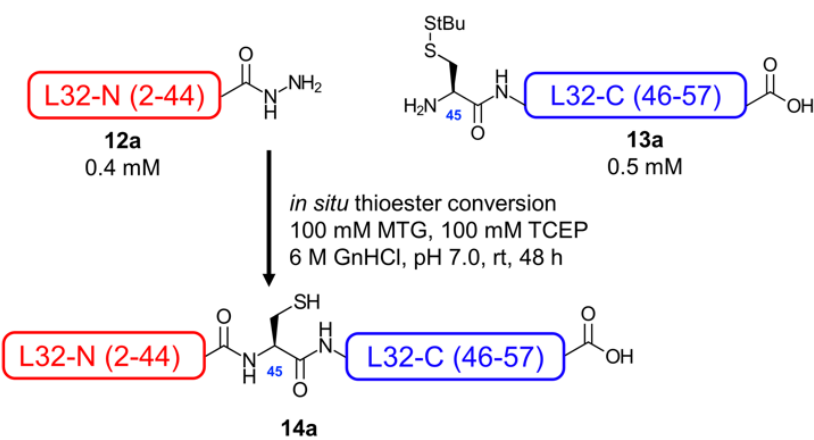

(C)

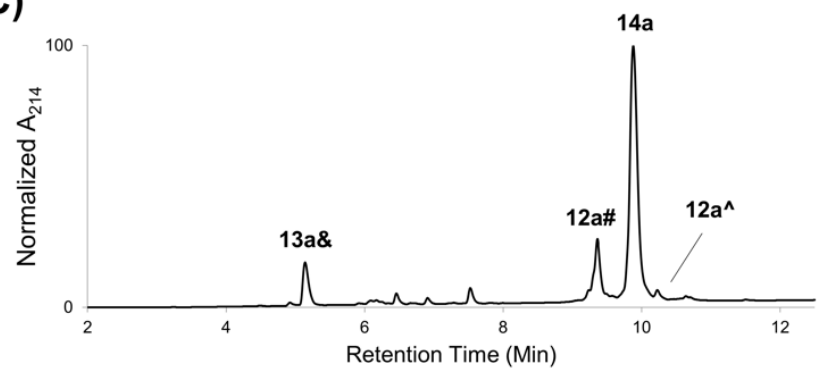

Figure 6: Non-templated native chemical ligation of $E$. coli $50 S$ ribosomal subunit L32 (14a). (A) Sequence of L32 with L32-N (2-44, red) and L32-C (45-57, blue). The cleaved initiator Met was excluded. (B) Simplified schematic of the non-templated NCL between L32-N (12a) and L32-C (13a). Note that MTG was allowed to form the thioester for $10 \mathrm{~min}$ prior to TCEP addition, as shown in the more detailed scheme (Scheme S3). (C) HPLC chromatogram of the ligation endpoint. The ligation was considered complete after $48 \mathrm{~h}$ (after MTG addition), as nearly all of the reactive L32-N peptide $\left(12 a^{\wedge}\right)$ was depleted. However, a significant amount of L32-N peptide underwent hydrolysis (12a\#) instead of ligation. 13a\& refers to StBudeprotected 13a. Analytical Method B was used. HPLC and LC/MS chromatograms of more time points are shown in Figures S89-90. 


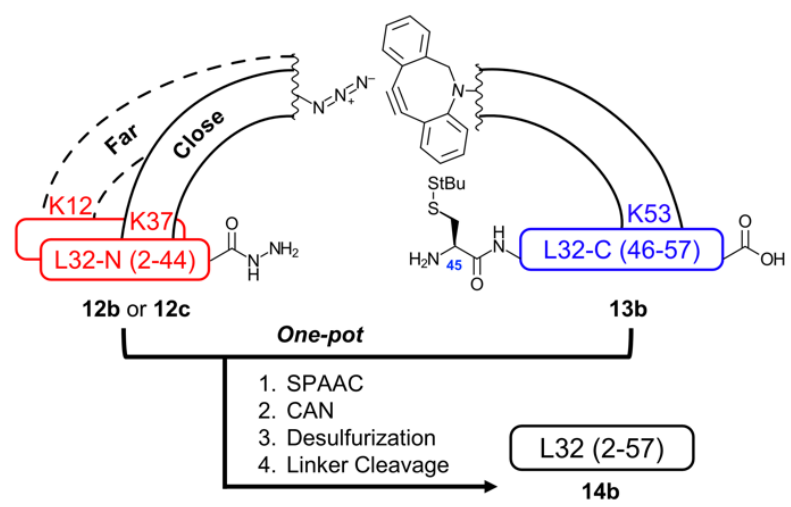

Scheme 2: One-pot SPAAC, CAN, desulfurization, and linker cleavage assembly strategy for L32-far (dotted line) and L32-close (solid line), showing location of Ddap attachment points at specified Lys residues. 


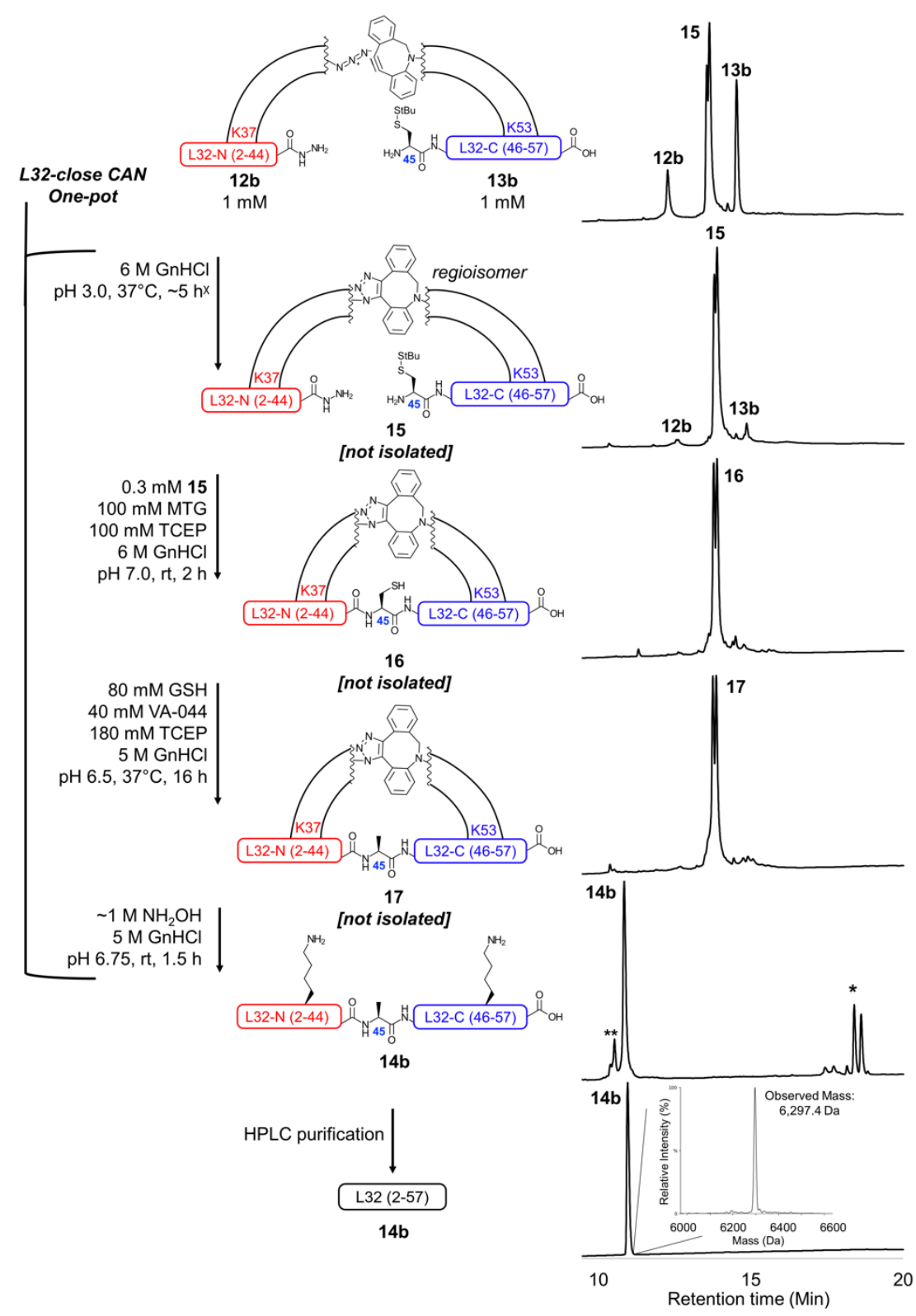

Figure 7: One-pot SPAAC, CAN, desulfurization, and linker cleavage of $\mathbf{1 2 b}$ and $\mathbf{1 3 b}$ to generate full-length L32$\mathrm{Nle}(14 \mathrm{~b})$. 12b and 13b were first templated together via $\sim 5 \mathrm{~h}$ SPAAC to produce triazole-linked 15 . The $\mathrm{x}$ in the reaction scheme indicates that additional 12b was added to the reaction after $4 \mathrm{~h}$, as a significant amount of unreacted 13b was observed (see more details in Scheme S4). CAN was then performed on $\mathbf{1 5}$ to efficiently generate 16 after only $2 \mathrm{~h}$. Desulfurization was then performed for $16 \mathrm{~h}$ to produce 17 . A $1.5 \mathrm{~h}$ linker cleavage of 17 resulted in 14b, which was easily HPLC purified. The HPLC chromatograms show, in descending order, $0 \mathrm{~h}$ and $\sim 5 \mathrm{~h}$ SPAAC, $2 \mathrm{~h}$ CAN (after MTG addition), $16 \mathrm{~h}$ desulfurization, $1.5 \mathrm{~h}$ linker cleavage, and purified 14b. The double peaks within the SPAAC, CAN, and desulfurization chromatograms are expected, as the triazole forms two regioisomers. * indicates cleaved Ddap linker peaks. There are more Ddap linker peaks in this chromatogram compared to the STEVEKENT CAN desulfurization chromatogram (Figure 4) due to Ddap hydrolysis occurring during desulfurization (Figure S100). ${ }^{* *}$ indicates hydrolyzed L32-N and desulfurized L32-C. The mass spectrum of purified 14b indicates that the correct full-length L32-Nle was generated (observed mass: 6,297.4 Da, calculated average mass: 6,297.1 Da). Analytical Method C and LC/MS Method C were used. HPLC and LC/MS chromatograms of additional time points taken for the SPAAC, CAN, desulfurization, linker cleavage, and purification are shown in Figures S96-102. 


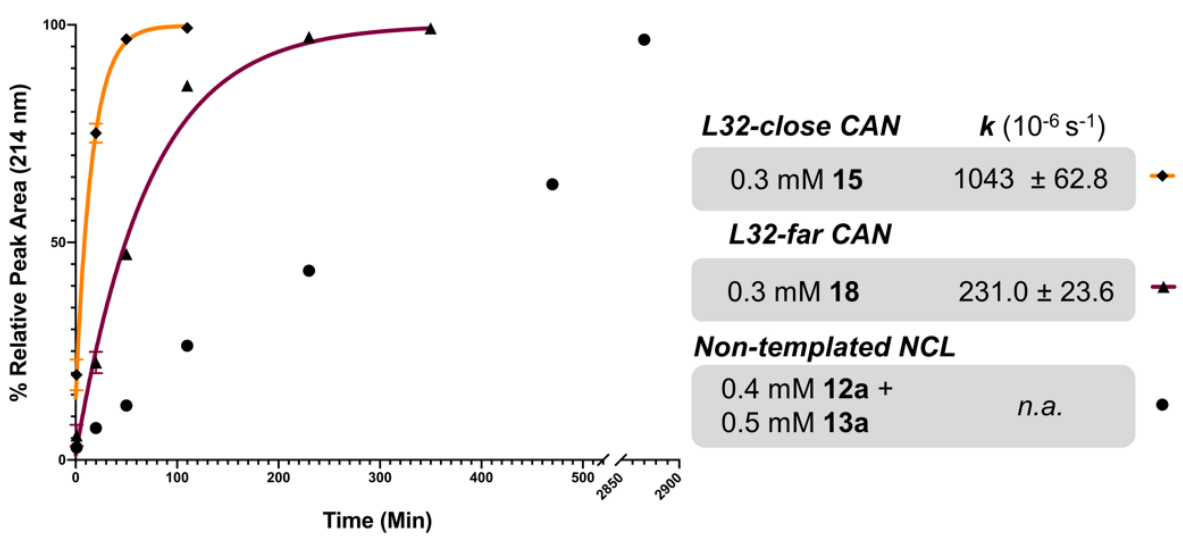

Figure 8: Comparison of non-templated NCL and CAN reaction rates using L32 peptides (12a, 13a, 15, and 18). Relative peak area of the ligated product is shown at various time points (relative to TCEP addition). CAN ligations were fit to first-order rate constants. For the non-templated NCL, peak areas of both product (14a) and L32-N reactant $\left(12 \mathrm{a}^{\wedge}\right)$ were calculated using estimated extinction coefficients, as described in the supplemental methods. Each data point represents the average of two independent experiments, with the error bars showing standard deviation. 


\section{ASSOCIATED CONTENT}

Materials, methods, supplemental tables, supplemental schemes, and supplemental figures are available in the supplementary information document. 


\section{AUTHOR INFORMATION}

\section{Corresponding Author}

*kay@biochem.utah.edu

\section{Present Address}

§Biological Sciences Division, Pacific Northwest National Laboratory, Richland, WA, USA 99354

\section{Author Contributions}

FThese authors contributed equally. The manuscript was written through contributions of all authors. All authors have given approval to the final version of the manuscript.

\section{Funding Sources}

Funding for this work was provided by a University of Utah Graduate Research Fellowship (to P.W.E.), the Marjorie Riches Gunn Award for Graduate Student Excellence (to J.M.F.), and NIH grants P50-Al150464 and R01-AI076168 (to M.S.K.).

\section{Notes}

The authors declare no competing financial interests. 


\section{ACKNOWLEDGMENT}

The authors would like to thank Aman Makaju, Anna Bakhtina, and Dr. Sarah Franklin for mass spectrometry analysis of trypsin-digested samples, and Dr. Diego Fernandez for ICP-MS analysis of peptides (ICP-MS Metals and Strontium Isotope Facility, University of Utah). We also thank the Synthetic and Medicinal Chemistry Core (University of Utah and USTAR) for synthesis of Fmoc-Ddap-OH. The authors also thank Adedeji Aderounmu, Dr. Weiliang Xu, Jonah Holbrook, Dr. Sarah Apple, Zachary Cruz, Judah Evangelista, and Riley Giesler for experimental/material assistance. We also thank Dr. Michael Jacobsen for experimental/material assistance, helpful discussions, and thoughtful advice. Finally, we thank Dr. Debra Eckert and Dr. Andrew Roberts for critical review of this manuscript. 


\section{ABBREVIATIONS}

$\mathrm{NCL}$, native chemical ligation

Ddap, N-Fmoc-2-(7-amino-1-hydroxyheptylidene)-5,5-dimethylcyclohexane-1,3-dione EDTA, Ethylenediaminetetraacetic acid

Fmoc, fluorenylmethoxycarbonyl

$\mathrm{GnHCl}$, guanidine hydrochloride

SPPS, solid-phase peptide synthesis

CAN, click-assisted native chemical ligation

DBCO, Dibenzocyclooctyne

ICP-MS, inductively coupled plasma mass spectrometry

RP-HPLC, reverse-phase high-performance liquid chromatography

LC/MS, liquid chromatography with mass spectrometry

TFA, trifluoroacetic acid

TIS, triisopropylsilane

AA, amino acid

$\mathrm{MeCN}$, acetonitrile 


\section{REFERENCES}

1. Merrifield, R. B., Solid Phase Peptide Synthesis. I. The Synthesis of a Tetrapeptide. Journal of the American Chemical Society 1963, 85 (14), 2149-2154.

2. Dawson, P. E.; Muir, T. W.; Clark-Lewis, I.; Kent, S. B., Synthesis of proteins by native chemical ligation. Science 1994, 266 (5186), 776-9.

3. Dawson, P. E.; Kent, S. B., Synthesis of native proteins by chemical ligation. Annu Rev Biochem 2000, 69, 923-60.

4. Wan, Q.; Danishefsky, S. J., Free-radical-based, specific desulfurization of cysteine: a powerful advance in the synthesis of polypeptides and glycopolypeptides. Angew Chem Int Ed Engl 2007, 46 (48), 9248-52.

5. Noisier, A. F. M.; Albericio, F., Advance in ligation techniques for peptide and protein synthesis. In Amino Acids, Peptides and Proteins, The Royal Society of Chemistry: 2014; Vol. 39, pp 1-20.

6. Kent, S. B. H., Novel protein science enabled by total chemical synthesis. Protein Sci 2019, 28 (2), 313-328.

7. $\quad$ Agouridas, V.; El Mahdi, O.; Diemer, V.; Cargoet, M.; Monbaliu, J. M.; Melnyk, O., Native Chemical Ligation and Extended Methods: Mechanisms, Catalysis, Scope, and Limitations. Chem Rev 2019, 119 (12), 7328-7443.

8. Chang, H. N.; Liu, B. Y.; Qi, Y. K.; Zhou, Y.; Chen, Y. P.; Pan, K. M.; Li, W. W.; Zhou, X. M.; Ma, W. W.; Fu, C. Y.; Qi, Y. M.; Liu, L.; Gao, Y. F., Blocking of the PD-1/PDL1 Interaction by a D-Peptide Antagonist for Cancer Immunotherapy. Angew Chem Int Ed Engl 2015, 54 (40), 11760-4.

9. Clinton, T. R.; Weinstock, M. T.; Jacobsen, M. T.; Szabo-Fresnais, N.; Pandya, M. J.; Whitby, F. G.; Herbert, A. S.; Prugar, L. I.; McKinnon, R.; Hill, C. P.; Welch, B. D.; Dye, J. M.; Eckert, D. M.; Kay, M. S., Design and characterization of ebolavirus GP prehairpin intermediate mimics as drug targets. Protein Sci 2015, 24 (4), 446-63.

10. Petersen, M. E.; Jacobsen, M. T.; Kay, M. S., Synthesis of tumor necrosis factor alpha for use as a mirror-image phage display target. Org Biomol Chem 2016, 14 (23), 5298-303.

11. Levinson, A. M.; McGee, J. H.; Roberts, A. G.; Creech, G. S.; Wang, T.; Peterson, M. T.; Hendrickson, R. C.; Verdine, G. L.; Danishefsky, S. J., Total Chemical Synthesis and Folding of All-I and All-d Variants of Oncogenic KRas(G12V). J Am Chem Soc 2017, 139 (22), 7632-7639.

12. De Rosa, L.; Di Stasi, R.; D'Andrea, L. D., Total chemical synthesis by native chemical ligation of the all-D immunoglobulin-like domain 2 of Axl. Tetrahedron 2019, 75 (7), 894-905.

13. Weinstock, M. T.; Jacobsen, M. T.; Kay, M. S., Synthesis and folding of a mirrorimage enzyme reveals ambidextrous chaperone activity. Proc Natl Acad Sci U S A 2014, 111 (32), 11679-84.

14. Vinogradov, A. A.; Evans, E. D.; Pentelute, B. L., Total synthesis and biochemical characterization of mirror image barnase. Chem Sci 2015, 6 (5), 2997-3002.

15. Wang, Z.; Xu, W.; Liu, L.; Zhu, T. F., A synthetic molecular system capable of mirror-image genetic replication and transcription. Nat Chem 2016, 8 (7), 698-704.

16. Jiang, W.; Zhang, B.; Fan, C.; Wang, M.; Wang, J.; Deng, Q.; Liu, X.; Chen, J.; Zheng, J.; Liu, L.; Zhu, T. F., Mirror-image polymerase chain reaction. Cell Discov 2017, $3,17037$. 
17. Pech, A.; Achenbach, J.; Jahnz, M.; Schulzchen, S.; Jarosch, F.; Bordusa, F.; Klussmann, S., A thermostable d-polymerase for mirror-image PCR. Nucleic Acids Res 2017, 45 (7), 3997-4005.

18. Xu, W.; Jiang, W.; Wang, J.; Yu, L.; Chen, J.; Liu, X.; Liu, L.; Zhu, T. F., Total chemical synthesis of a thermostable enzyme capable of polymerase chain reaction. Cell Discov 2017, 3, 17008.

19. Mandal, K.; Uppalapati, M.; Ault-Riche, D.; Kenney, J.; Lowitz, J.; Sidhu, S. S.; Kent, S. B., Chemical synthesis and X-ray structure of a heterochiral $\{\mathrm{D}$-protein antagonist plus vascular endothelial growth factor\} protein complex by racemic crystallography. Proc Natl Acad Sci U S A 2012, 109 (37), 14779-84.

20. Yan, B.; Ye, L.; Xu, W.; Liu, L., Recent advances in racemic protein crystallography. Bioorg Med Chem 2017, 25 (18), 4953-4965.

21. Kent, S. B., Racemic \& quasi-racemic protein crystallography enabled by chemical protein synthesis. Curr Opin Chem Biol 2018, 46, 1-9.

22. Chen, C. C.; Gao, S.; Ai, H. S.; Qu, Q.; Tian, C. L.; Li, Y. M., Racemic X-ray structure of L-type calcium channel antagonist Calciseptine prepared by total chemical synthesis. Sci China Chem 2018, 61 (6), 702-707.

23. Jbara, M.; Laps, S.; Morgan, M.; Kamnesky, G.; Mann, G.; Wolberger, C.; Brik, A., Palladium prompted on-demand cysteine chemistry for the synthesis of challenging and uniquely modified proteins. Nat Commun 2018, 9 (1), 3154.

24. Lewis, Y. E.; Galesic, A.; Levine, P. M.; De Leon, C. A.; Lamiri, N.; Brennan, C. K.; Pratt, M. R., O-GlcNAcylation of alpha-Synuclein at Serine 87 Reduces Aggregation without Affecting Membrane Binding. ACS Chem Biol 2017, 12 (4), 1020-1027.

25. Araman, C.; Thompson, R. E.; Wang, S.; Hackl, S.; Payne, R. J.; Becker, C. F. W., Semisynthetic prion protein (PrP) variants carrying glycan mimics at position 181 and 197 do not form fibrils. Chem Sci 2017, 8 (9), 6626-6632.

26. Lechner, C. C.; Agashe, N. D.; Fierz, B., Traceless Synthesis of Asymmetrically Modified Bivalent Nucleosomes. Angew Chem Int Ed Engl 2016, 55 (8), 2903-6.

27. Sun, H.; Brik, A., The Journey for the Total Chemical Synthesis of a $53 \mathrm{kDa}$ Protein. Acc Chem Res 2019.

28. Giesler, R. J.; Fulcher, J. M.; Jacobsen, M. T.; Kay, M. S., Controlling segment solubility in large protein synthesis. In Total Chemical Synthesis of Proteins, Brik, A.; Dawson, P. E.; Liu, L., Eds. In press: 2020.

29. Jacobsen, M. T.; Petersen, M. E.; Ye, X.; Galibert, M.; Lorimer, G. H.; Aucagne, V.; Kay, M. S., A Helping Hand to Overcome Solubility Challenges in Chemical Protein Synthesis. Journal of the American Chemical Society 2016, 138 (36), 11775-11782.

30. Zhao, D. D.; Fan, X. W.; Hao, H.; Zhang, H. L.; Guo, Y., Temporary Solubilizing Tags Method for the Chemical Synthesis of Hydrophobic Proteins. Curr Org Chem 2019, 23 (1), 2-13.

31. Yoshiya, T.; Tsuda, S.; Masuda, S., Development of Trityl Group Anchored Solubilizing Tags for Peptide and Protein Synthesis. Chembiochem 2019, 20 (15), 19061913.

32. Saito, F.; Noda, H.; Bode, J. W., Critical evaluation and rate constants of chemoselective ligation reactions for stoichiometric conjugations in water. ACS Chem Biol 2015, 10 (4), 1026-33. 
33. Roberts, A. G.; Johnston, E. V.; Shieh, J. H.; Sondey, J. P.; Hendrickson, R. C.; Moore, M. A.; Danishefsky, S. J., Fully Synthetic Granulocyte Colony-Stimulating Factor Enabled by Isonitrile-Mediated Coupling of Large, Side-Chain-Unprotected Peptides. $J$ Am Chem Soc 2015, 137 (40), 13167-75.

34. Chen, J.; Wan, Q.; Yuan, Y.; Zhu, J.; Danishefsky, S. J., Native chemical ligation at valine: a contribution to peptide and glycopeptide synthesis. Angew Chem Int Ed Engl 2008, 47 (44), 8521-4.

35. Haase, C.; Rohde, H.; Seitz, O., Native chemical ligation at valine. Angew Chem Int Edit 2008, 47 (36), 6807-6810.

36. Chen, H.; Xiao, Y.; Yuan, N.; Weng, J.; Gao, P.; Breindel, L.; Shekhtman, A.; Zhang, Q., Coupling of sterically demanding peptides by $\beta$-thiolactone-mediated native chemical ligation. Chemical Science 2018, 9 (7), 1982-1988.

37. Hackeng, T. M.; Griffin, J. H.; Dawson, P. E., Protein synthesis by native chemical ligation: expanded scope by using straightforward methodology. Proc Natl Acad Sci U S A 1999, 96 (18), 10068-73.

38. Conibear, A. C.; Watson, E. E.; Payne, R. J.; Becker, C. F. W., Native chemical ligation in protein synthesis and semi-synthesis. Chem Soc Rev 2018, 47 (24), 90469068.

39. Dawson, P. E.; Churchill, M. J.; Ghadiri, M. R.; Kent, S. B. H., Modulation of reactivity in native chemical ligation through the use of thiol additives. Journal of the American Chemical Society 1997, 119 (19), 4325-4329.

40. Johnson, E. C. B.; Kent, S. B. H., Insights into the mechanism and catalysis of the native chemical ligation reaction. Journal of the American Chemical Society 2006, 128 (20), 6640-6646.

41. Thompson, R. E.; Liu, X.; Alonso-Garcia, N.; Pereira, P. J.; Jolliffe, K. A.; Payne, R. J., Trifluoroethanethiol: an additive for efficient one-pot peptide ligation-desulfurization chemistry. J Am Chem Soc 2014, 136 (23), 8161-4.

42. Kumar, K. S.; Bavikar, S. N.; Spasser, L.; Moyal, T.; Ohayon, S.; Brik, A., Total chemical synthesis of a 304 amino acid K48-linked tetraubiquitin protein. Angew Chem Int Ed Engl 2011, 50 (27), 6137-41.

43. Sakamoto, K.; Tsuda, S.; Mochizuki, M.; Nohara, Y.; Nishio, H.; Yoshiya, T., Imidazole-Aided Native Chemical Ligation: Imidazole as a One-Pot DesulfurizationAmenable Non-Thiol-Type Alternative to 4-Mercaptophenylacetic Acid. Chemistry 2016, 22 (50), 17940-17944.

44. Kemp, D. S.; Leung, S.-L.; Kerkman, D. J., Models that demonstrate peptide bond formation by prior thiol capture I. Capture by disulfide formation. Tetrahedron Letters 1981, $22(3), 181-184$.

45. Kemp, D. S.; Galakatos, N. G.; Bowen, B.; Tan, K., Peptide synthesis by prior thiol capture. 2. Design of templates for intramolecular O,N-acyl transfer. 4,6-Disubstituted dibenzofurans as optimal spacing elements. The Journal of Organic Chemistry 1986, 51 (10), 1829-1838.

46. Tam, J. P.; Wong, C. T. T., Chemical Synthesis of Circular Proteins. Journal of Biological Chemistry 2012, 287 (32), 27020-27025.

47. Lin, H.; Thayer, D. A.; Wong, C.-H.; Walsh, C. T., Macrolactamization of Glycosylated Peptide Thioesters by the Thioesterase Domain of Tyrocidine Synthetase. Chemistry \& Biology 2004, 11 (12), 1635-1642. 
48. Meutermans, W. D. F.; Bourne, G. T.; Golding, S. W.; Horton, D. A.; Campitelli, M. R.; Craik, D.; Scanlon, M.; Smythe, M. L., Difficult Macrocyclizations: New Strategies for Synthesizing Highly Strained Cyclic Tetrapeptides. Organic Letters 2003, 5 (15), 27112714.

49. Sengupta, S.; Mehta, G., Macrocyclization via C-H functionalization: a new paradigm in macrocycle synthesis. Organic \& Biomolecular Chemistry 2020, 18 (10), 1851-1876.

50. Lee, D. H.; Granja, J. R.; Martinez, J. A.; Severin, K.; Ghadiri, M. R., A selfreplicating peptide. Nature 1996, 382 (6591), 525-8.

51. Yao, S.; Ghosh, I.; Zutshi, R.; Chmielewski, J., A pH-modulated, self-replicating peptide. Journal of the American Chemical Society 1997, 119 (43), 10559-10560.

52. Beligere, G. S.; Dawson, P. E., Conformationally assisted protein ligation using Cterminal thioester peptides. Journal of the American Chemical Society 1999, 121 (26), 6332-6333.

53. Rubinov, B.; Wagner, N.; Rapaport, H.; Ashkenasy, G., Self-Replicating Amphiphilic beta-Sheet Peptides. Angew Chem Int Edit 2009, 48 (36), 6683-6686.

54. Reinhardt, U.; Lotze, J.; Zernia, S.; Morl, K.; Beck-Sickinger, A. G.; Seitz, O., Peptide-templated acyl transfer: a chemical method for the labeling of membrane proteins on live cells. Angew Chem Int Ed Engl 2014, 53 (38), 10237-41.

55. Reinhardt, U.; Lotze, J.; Morl, K.; Beck-Sickinger, A. G.; Seitz, O., Rapid Covalent Fluorescence Labeling of Membrane Proteins on Live Cells via Coiled-Coil Templated Acyl Transfer. Bioconjugate Chem 2015, 26 (10), 2106-2117.

56. Lotze, J.; Reinhardt, U.; Seitz, O.; Beck-Sickinger, A. G., Peptide-tags for sitespecific protein labelling in vitro and in vivo. Mol Biosyst 2016, 12 (6), 1731-45.

57. Petszulat, H.; Seitz, O., A fluorogenic native chemical ligation for assessing the role of distance in peptide-templated peptide ligation. Bioorg Med Chem 2017, 25 (18), 5022-5030.

58. Bruick, R. K.; Dawson, P. E.; Kent, S. B.; Usman, N.; Joyce, G. F., Templatedirected ligation of peptides to oligonucleotides. Chem Biol 1996, 3 (1), 49-56.

59. Vazquez, O.; Seitz, O., Templated native chemical ligation: peptide chemistry beyond protein synthesis. J Pept Sci 2014, 20 (2), 78-86.

60. Michaelis, J.; Roloff, A.; Seitz, O., Amplification by nucleic acid-templated reactions. Org Biomol Chem 2014, 12 (18), 2821-33.

61. Di Pisa, M.; Seitz, O., Nucleic Acid Templated Reactions for Chemical Biology. ChemMedChem 2017, 12 (12), 872-882.

62. Lores Lareo, P.; Linscheid, M. W.; Seitz, O., Nucleic acid and SNP detection via template-directed native chemical ligation and inductively coupled plasma mass spectrometry. J Mass Spectrom 2019, 54 (8), 676-683.

63. Sayers, J.; Payne, R. J.; Winssinger, N., Peptide nucleic acid-templated selenocystine-selenoester ligation enables rapid miRNA detection. Chem Sci 2018, 9 (4), 896-903.

64. Middel, S.; Panse, C. H.; Nawratil, S.; Diederichsen, U., Native Chemical Ligation Directed by Photocleavable Peptide Nucleic Acid (PNA) Templates. Chembiochem 2017, 18 (23), 2328-2332. 
65. Hayashi, G.; Yanase, M.; Nakatsuka, Y.; Okamoto, A., Simultaneous and Traceless Ligation of Peptide Fragments on DNA Scaffold. Biomacromolecules 2019, 20 (3), 1246-1253.

66. Pattison, D. I.; Rahmanto, A. S.; Davies, M. J., Photo-oxidation of proteins. Photochem Photobiol Sci 2012, 11 (1), 38-53.

67. Li, S.; Cai, H.; He, J.; Chen, H.; Lam, S.; Cai, T.; Zhu, Z.; Bark, S. J.; Cai, C., Extent of the Oxidative Side Reactions to Peptides and Proteins During the CuAAC Reaction. Bioconjug Chem 2016, 27 (10), 2315-2322.

68. Conibear, A. C.; Farbiarz, K.; Mayer, R. L.; Matveenko, M.; Kahlig, H.; Becker, C. F., Arginine side-chain modification that occurs during copper-catalysed azide-alkyne click reactions resembles an advanced glycation end product. Org Biomol Chem 2016, 14 (26), 6205-11.

69. Osuna Galvez, A.; Bode, J. W., Traceless Templated Amide-Forming Ligations. J Am Chem Soc 2019, 141 (22), 8721-8726.

70. Fulcher, J. M.; Petersen, M. E.; Giesler, R. J.; Cruz, Z. S.; Eckert, D. M.; Francis, J. N.; Kawamoto, E. M.; Jacobsen, M. T.; Kay, M. S., Chemical synthesis of Shiga toxin subunit B using a next-generation traceless "helping hand" solubilizing tag. Org Biomol Chem 2019, 17 (48), 10237-10244.

71. Huang, Y. C.; Chen, C. C.; Gao, S.; Wang, Y. H.; Xiao, H.; Wang, F.; Tian, C. L.; $\mathrm{Li}, \mathrm{Y}$. M., Synthesis of $\mathrm{I}$ - and d-Ubiquitin by One-Pot Ligation and Metal-Free Desulfurization. Chemistry 2016, 22 (22), 7623-8.

72. Jewett, J. C.; Bertozzi, C. R., Cu-free click cycloaddition reactions in chemical biology. Chem Soc Rev 2010, 39 (4), 1272-9.

73. Jewett, J. C.; Sletten, E. M.; Bertozzi, C. R., Rapid Cu-free click chemistry with readily synthesized biarylazacyclooctynones. J Am Chem Soc 2010, 132 (11), 3688-90.

74. Wang, Q.; Chan, T. R.; Hilgraf, R.; Fokin, V. V.; Sharpless, K. B.; Finn, M. G., Bioconjugation by copper(I)-catalyzed azide-alkyne [3 + 2] cycloaddition. J Am Chem Soc 2003, 125 (11), 3192-3.

75. Lee, D. J.; Mandal, K.; Harris, P. W.; Brimble, M. A.; Kent, S. B., A one-pot approach to neoglycopeptides using orthogonal native chemical ligation and click chemistry. Org Lett 2009, 11 (22), 5270-3.

76. Zheng, J. S.; Tang, S.; Qi, Y. K.; Wang, Z. P.; Liu, L., Chemical synthesis of proteins using peptide hydrazides as thioester surrogates. Nature Protocols 2013, 8 (12), 2483-2495.

77. Schneggenburger, P. E.; Worbs, B.; Diederichsen, U., Azide reduction during peptide cleavage from solid support-the choice of thioscavenger? J Pept Sci 2010, 16 (1), 10-4.

78. Kizil, C.; Iltzsche, A.; Thomas, A. K.; Bhattarai, P.; Zhang, Y. X.; Brand, M., Efficient Cargo Delivery into Adult Brain Tissue Using Short Cell-Penetrating Peptides. Plos One 2015, 10 (4).

79. Perols, A.; Arcos Famme, M.; Eriksson Karlstrom, A., Site-Specific Antibody Labeling by Covalent Photoconjugation of Z Domains Functionalized for Alkyne-Azide Cycloaddition Reactions. Chembiochem 2015, 16 (17), 2522-9.

80. Witte, M. D.; Theile, C. S.; Wu, T.; Guimaraes, C. P.; Blom, A. E.; Ploegh, H. L., Production of unnaturally linked chimeric proteins using a combination of sortasecatalyzed transpeptidation and click chemistry. Nat Protoc 2013, 8 (9), 1808-19. 
81. Huey, L., Development of a Monodisperse Oligomeric Hemoglobin-Based Oxygen Carrier for Acute Blood Replacement Therapy. WWU Honors Program Senior Projects 2018, 83.

82. Wang, X. X.; Gobbo, P.; Suchy, M.; Workentin, M. S.; Hudson, R. H. E., Peptidedecorated gold nanoparticles via strain-promoted azide-alkyne cycloaddition and post assembly deprotection. Rsc Adv 2014, 4 (81), 43087-43091.

83. Chigrinova, M.; McKay, C. S.; Beaulieu, L. P.; Udachin, K. A.; Beauchemin, A. M.; Pezacki, J. P., Rearrangements and addition reactions of biarylazacyclooctynones and the implications to copper-free click chemistry. Org Biomol Chem 2013, 11 (21), 3436-41. 84. Debets, M. F.; van Berkel, S. S.; Schoffelen, S.; Rutjes, F. P.; van Hest, J. C.; van Delft, F. L., Aza-dibenzocyclooctynes for fast and efficient enzyme PEGylation via copperfree (3+2) cycloaddition. Chem Commun (Camb) 2010, 46 (1), 97-9.

85. Loy, D. M.; Klein, P. M.; Krzysztoń, R.; Lächelt, U.; Rädler, J. O.; Wagner, E., A microfluidic approach for sequential assembly of siRNA polyplexes with defined structure - activity relationship. PeerJ Preprints 2019.

86. Klein, P. M.; Wagner, E., Click-Shielded and Targeted Lipopolyplexes. Methods Mol Biol 2019, 2036, 141-164.

87. van Geel, R.; Pruijn, G. J.; van Delft, F. L.; Boelens, W. C., Preventing thiol-yne addition improves the specificity of strain-promoted azide-alkyne cycloaddition. Bioconjug Chem 2012, 23 (3), 392-8.

88. Yoshida, S.; Hatakeyama, Y.; Johmoto, K.; Uekusa, H.; Hosoya, T., Transient protection of strained alkynes from click reaction via complexation with copper. J Am Chem Soc 2014, 136 (39), 13590-3.

89. Yoshida, S.; Kuribara, T.; Ito, H.; Meguro, T.; Nishiyama, Y.; Karaki, F.; Hatakeyama, Y.; Koike, Y.; Kii, I.; Hosoya, T., A facile preparation of functional cycloalkynes via an azide-to-cycloalkyne switching approach. Chem Commun (Camb) 2019, 55 (24), 3556-3559.

90. Bennett, M. A.; Schwemlein, H. P., Metal-Complexes of Small Cycloalkynes and Arynes. Angew Chem Int Edit 1989, 28 (10), 1296-1320.

91. Vilaseca, M.; Nicolas, E.; Capdevila, F.; Giralt, E., Reduction of methionine sulfoxide with NH4I/TFA: Compatibility with peptides containing cysteine and aromatic amino acids. Tetrahedron 1998, 54 (50), 15273-15286.

92. Huang, H.; Rabenstein, D. L., A cleavage cocktail for methionine-containing peptides. J Pept Res 1999, 53 (5), 548-53.

93. Li, J.; Li, Y.; He, Q.; Li, Y.; Li, H.; Liu, L., One-pot native chemical ligation of peptide hydrazides enables total synthesis of modified histones. Org Biomol Chem 2014, 12 (29), 5435-41.

94. Ohayon, S.; Spasser, L.; Aharoni, A.; Brik, A., Targeting deubiquitinases enabled by chemical synthesis of proteins. J Am Chem Soc 2012, 134 (6), 3281-9.

95. Spicer, C. D.; Jumeaux, C.; Gupta, B.; Stevens, M. M., Peptide and protein nanoparticle conjugates: versatile platforms for biomedical applications. Chem Soc Rev 2018, 47 (10), 3574-3620.

96. Liu, Y.; Conboy, M. J.; Mehdipour, M.; Liu, Y.; Tran, T. P.; Blotnick, A.; Rajan, P.; Santos, T. C.; Conboy, I. M., Application of bio-orthogonal proteome labeling to cell transplantation and heterochronic parabiosis. Nat Commun 2017, 8 (1), 643. 
97. Yang, A. C.; du Bois, H.; Olsson, N.; Gate, D.; Lehallier, B.; Berdnik, D.; Brewer, K. D.; Bertozzi, C. R.; Elias, J. E.; Wyss-Coray, T., Multiple Click-Selective tRNA Synthetases Expand Mammalian Cell-Specific Proteomics. J Am Chem Soc 2018, 140 (23), 7046-7051.

98. Merten, H.; Schaefer, J. V.; Brandl, F.; Zangemeister-Wittke, U.; Pluckthun, A., Facile Site-Specific Multiconjugation Strategies in Recombinant Proteins Produced in Bacteria. Methods Mol Biol 2019, 2033, 253-273.

99. Saleh, A. M.; Wilding, K. M.; Calve, S.; Bundy, B. C.; Kinzer-Ursem, T. L., Noncanonical amino acid labeling in proteomics and biotechnology. J Biol Eng 2019, 13, 43. 100. Lee, K. J.; Kang, D.; Park, H. S., Site-Specific Labeling of Proteins Using Unnatural Amino Acids. Mol Cells 2019, 42 (5), 386-396.

101. Plass, T.; Milles, S.; Koehler, C.; Schultz, C.; Lemke, E. A., Genetically encoded copper-free click chemistry. Angew Chem Int Ed Engl 2011, 50 (17), 3878-81.

102. Borrmann, A.; Milles, S.; Plass, T.; Dommerholt, J.; Verkade, J. M.; Wiessler, M.; Schultz, C.; van Hest, J. C.; van Delft, F. L.; Lemke, E. A., Genetic encoding of a bicyclo[6.1.0]nonyne-charged amino acid enables fast cellular protein imaging by metalfree ligation. Chembiochem 2012, 13 (14), 2094-9.

103. Lang, K.; Davis, L.; Wallace, S.; Mahesh, M.; Cox, D. J.; Blackman, M. L.; Fox, J. M.; Chin, J. W., Genetic Encoding of bicyclononynes and trans-cyclooctenes for sitespecific protein labeling in vitro and in live mammalian cells via rapid fluorogenic DielsAlder reactions. J Am Chem Soc 2012, 134 (25), 10317-20.

104. Alamudi, S. H.; Satapathy, R.; Kim, J.; Su, D.; Ren, H.; Das, R.; Hu, L.; AlvaradoMartinez, E.; Lee, J. Y.; Hoppmann, C.; Pena-Cabrera, E.; Ha, H. H.; Park, H. S.; Wang, L.; Chang, Y. T., Development of background-free tame fluorescent probes for intracellular live cell imaging. Nat Commun 2016, 7, 11964.

105. Baldwin, J. E., Rules for Ring-Closure. J Chem Soc Chem Comm 1976, (18), 734736.

106. Gobbo, P.; Romagnoli, T.; Barbon, S. M.; Price, J. T.; Keir, J.; Gilroy, J. B.; Workentin, M. S., Expanding the scope of strained-alkyne chemistry: a protectiondeprotection strategy via the formation of a dicobalt-hexacarbonyl complex. Chem Commun (Camb) 2015, 51 (30), 6647-50.

107. Zayas, J.; Annoual, M.; Das, J. K.; Felty, Q.; Gonzalez, W. G.; Miksovska, J.; Sharifai, N.; Chiba, A.; Wnuk, S. F., Strain Promoted Click Chemistry of 2- or 8Azidopurine and 5-Azidopyrimidine Nucleosides and 8-Azidoadenosine Triphosphate with Cyclooctynes. Application to Living Cell Fluorescent Imaging. Bioconjugate Chem 2015, 26 (8), 1519-1532.

108. Dommerholt, J.; Rutjes, F. P. J. T.; van Delft, F. L., Strain-Promoted 1,3-Dipolar Cycloaddition of Cycloalkynes and Organic Azides. Top Curr Chem (Cham) 2016, 374 (2), 16-16.

109. Jacobsen, M. T.; Erickson, P. W.; Kay, M. S., Aligator: A computational tool for optimizing total chemical synthesis of large proteins. Bioorg Med Chem 2017, 25 (18), 4946-4952. 